\title{
Validation of water vapour profiles (version 13) retrieved by the IMK/IAA scientific retrieval processor based on full resolution spectra measured by MIPAS on board Envisat
}

\author{
M. Milz ${ }^{1}$, T. v. Clarmann ${ }^{2}$, P. Bernath ${ }^{3,4}$, C. Boone $^{4}$, S. A. Buehler ${ }^{1}$, S. Chauhan ${ }^{2}$, B. Deuber ${ }^{5}$, D. G. Feist ${ }^{6}$, B. Funke ${ }^{7}$, \\ N. Glatthor ${ }^{2}$, U. Grabowski ${ }^{2}$, A. Griesfeller ${ }^{8}$, A. Haefele ${ }^{5}$, M. Höpfner ${ }^{2}$, N. Kämpfer ${ }^{5}$, S. Kellmann ${ }^{2}$, A. Linden ${ }^{2}$, \\ S. Müller ${ }^{5, *}$, H. Nakajima ${ }^{9}$, H. Oelhaf ${ }^{2}$, E. Remsberg ${ }^{10}$, S. Rohs ${ }^{11}$, J. M. Russell III ${ }^{15}$, C. Schiller ${ }^{11}$, G. P. Stiller ${ }^{2}$, \\ T. Sugita ${ }^{9}$, T. Tanaka ${ }^{9}$, H. Vömel ${ }^{12, * *}$, K. Walker ${ }^{4,13}$, G. Wetzel ${ }^{2}$, T. Yokota ${ }^{9}$, V. Yushkov ${ }^{14}$, and G. Zhang ${ }^{2, * * *}$ \\ ${ }^{1}$ Luleå Technical University, Dept. of Space Science, Kiruna, Sweden \\ ${ }^{2}$ Forschungszentrum Karlsruhe and Universität Karlsruhe, Institut für Meteorologie und Klimaforschung, Karlsruhe, Germany \\ ${ }^{3}$ Department of Chemistry, University of York, York, UK \\ ${ }^{4}$ Department of Chemistry, University of Waterloo, Ontario, Canada \\ ${ }^{5}$ Institute of Applied Physics, Atmospheric Physics Group, University of Bern, Bern, Switzerland \\ ${ }^{6}$ Max Planck Institute for Biogeochemistry, Jena, Germany \\ ${ }^{7}$ Instituto de Astrofísica de Andalucía, CSIC, Granada, Spain \\ ${ }^{8}$ Laboratoire Atmosphères, Milieux, Observations Spatiales (LATMOS), UVSQ, CNRS, Verrières-le-Buisson, France \\ ${ }^{9}$ National Institute for Environmental Studies (NIES), Tsukuba, Japan \\ ${ }^{10}$ Science Directorate, NASA Langley Research Center, Hampton, Virginia, USA \\ ${ }^{11}$ Forschungszentrum Jülich GmbH, Jülich, Germany \\ ${ }^{12}$ Cooperative Institute for Environmental Sciences, University of Colorado, Boulder, USA \\ ${ }^{13}$ Department of Physics, University of Toronto, Ontario, Canada \\ ${ }^{14}$ Central Aerological Observatory, Dolgoprudny, Russia \\ ${ }^{15}$ Department of Physics, Hampton University, Hampton, USA \\ *now at: METEOTEST, Bern, Switzerland \\ ${ }^{* * *}$ now at: Deutscher Wetterdienst, Meteorologisches Observatorium Lindenberg, Lindenberg, Germany \\ **** now at: Dept. of Physics and Information Engineering,Shangqiu Normal University, Shangqiu, China
}

Received: 9 January 2009 - Published in Atmos. Meas. Tech. Discuss.: 25 February 2009

Revised: 9 June 2009 - Accepted: 19 June 2009 - Published: 27 July 2009

\begin{abstract}
Vertical profiles of stratospheric water vapour measured by the Michelson Interferometer for Passive Atmospheric Sounding (MIPAS) with the full resolution mode between September 2002 and March 2004 and retrieved with the IMK/IAA scientific retrieval processor were compared to a number of independent measurements in order to estimate the bias and to validate the existing precision estimates of the MIPAS data. The estimated precision for MIPAS is 5 to $10 \%$ in the stratosphere, depending on altitude, latitude, and season. The independent instruments were: the Halogen Occultation Experiment (HALOE), the Atmospheric Chemistry Experiment Fourier Transform Spectrometer (ACE-FTS), the Improved Limb Atmospheric Spectrometer-II (ILAS-II),
\end{abstract}

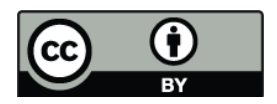

Correspondence to: $\mathrm{M}$. Milz (mathias.milz@ltu.se) the Polar Ozone and Aerosol Measurement (POAM III) instrument, the Middle Atmospheric Water Vapour Radiometer (MIAWARA), the Michelson Interferometer for Passive Atmospheric Sounding, balloon-borne version (MIPAS-B), the Airborne Microwave Stratospheric Observing System (AMSOS), the Fluorescent Stratospheric Hygrometer for Balloon (FLASH-B), the NOAA frostpoint hygrometer, and the Fast In Situ Hygrometer (FISH). For the in-situ measurements and the ground based, air- and balloon borne remote sensing instruments, the measurements are restricted to central and northern Europe. The comparisons to satellite-borne instruments are predominantly at mid- to high latitudes on both hemispheres. In the stratosphere there is no clear indication of a bias in MIPAS data, because the independent measurements in some cases are drier and in some cases are moister than the MIPAS measurements. Compared to the infrared measurements of MIPAS, measurements in the

Published by Copernicus Publications on behalf of the European Geosciences Union. 
ultraviolet and visible have a tendency to be high, whereas microwave measurements have a tendency to be low. The results of $\chi^{2}$-based precision validation are somewhat controversial among the comparison estimates. However, for comparison instruments whose error budget also includes errors due to uncertainties in spectrally interfering species and where good coincidences were found, the $\chi^{2}$ values found are in the expected range or even below. This suggests that there is no evidence of systematically underestimated MIPAS random errors.

\section{Introduction}

Water vapour in the upper troposphere and stratosphere is of great importance for several reasons. It is a greenhouse gas and plays a dominant role in the radiative budget of the Earth. In the troposphere water vapour and clouds are part of the hydrological cycle. In the stratosphere water vapour is a good tracer for atmospheric motions, e.g. for diagnosing stratosphere-troposphere exchange processes and large scale circulation. Stratospheric water vapour influences the atmospheric chemistry e.g. due to its role in the formation of polar stratospheric clouds (PSCs) and in providing $\mathrm{HO}_{\mathrm{x}}$ which plays a role in stratospheric chemistry.

Satellite-borne instruments offer the opportunity to measure stratospheric water vapour with global coverage. One such instrument is the Michelson Interferometer for Passive Atmospheric Sounding (MIPAS) on board the research satellite Envisat, operated by the European Space Agency (ESA). MIPAS is a Fourier transform spectrometer operating in a limb-viewing mode, measuring the emission of the Earth's atmosphere in the infrared (Fischer et al., 2008). Envisat was launched on 1 March 2002 and operates at an altitude of approximately $800 \mathrm{~km}$ in a sun-synchronous polar orbit with equatorial local crossing times of 10:00 and 22:00 in descending and ascending node, respectively. The orbital period is about $100 \mathrm{~min}$. The measurement time of one single limb scan is about $75 \mathrm{~s}$ and - in the original nominal measurement mode used from July 2002 to 25 March 2004 consists of 17 tangent altitudes between 6 and $68 \mathrm{~km}$, with $3 \mathrm{~km}$ spacing from 6 to $42 \mathrm{~km}$ and coarser spacing above. The vertical instantaneous field of view (FOV) is approximately $3 \mathrm{~km}$. The generation of calibrated radiance spectra, so-called level $1 \mathrm{~b}$ data, is performed by ESA (Nett et al., 1999), as well as the retrieval of vertical profiles of temperature and atmospheric constituents including water vapour (Ridolfi et al., 2000; Raspollini et al., 2006). Besides ESA, several institutes operate their own scientific data processors for retrieval of atmospheric state variables (von Clarmann et al., 2003). One of these processors is the scientific MIPAS processor - developed by the "Institut für Meteorologie und Klimaforschung", Karlsruhe, Germany (IMK) and the "In- stituto de Astrofísica de Andalucía”, Granada, Spain (IAA) - of which the $\mathrm{H}_{2} \mathrm{O}$ data product is validated in this paper.

\section{IMK/IAA water vapour data}

A description of the retrieval approach for IMK/IAA water vapour products can be found in Milz et al. (2005). The IMK processing aims at the retrieval of reliable $\mathrm{H}_{2} \mathrm{O}$ data in a wider altitude range than possible with operational processing under ESA responsibility. Furthermore, the accessibility of diagnostic data such as averaging kernels and covariance matrices for each individual profile are an advantage of IMK/IAA data in the context of quantitative scientific use. However, the disadvantage of the IMK/IAA data set is its limited temporal coverage. Since the production of the IMK/IAA data set requires much more computational resources than that of ESA data, only particular episodes have been analyzed so far. The main differences with respect to the operational $\mathrm{H}_{2} \mathrm{O}$ retrieval under ESA responsibility are (1) a different choice of spectral lines used for analysis, (2) the representation of the vertical profile on a fine vertical grid ( $1 \mathrm{~km}$ from $6-42 \mathrm{~km}$ altitude) independent of the actual tangent altitudes, (3) application of regularization instead of a pure maximum likelihood retrieval, and (4) a different choice of retrieval parameters such as cloud detection parameters (Spang et al., 2004) or convergence criteria. The IMK/IAA data sets are available to registered users on http://www-imk.fzk.de/asf/sat/envisat-data/.

The data presented in Milz et al. (2005) are IMK version H2O_V1_5 and H2O_V2_5 and were retrieved based on ESA near real time level $1 \mathrm{~b}$ products. The data used in this paper are H2O_V3O_13 and are based on ESA level $1 \mathrm{~b}$ spectra obtained from the off-line processing. The spectra are expected to be of better and consistent quality for the whole period covered by MIPAS full resolution measurements. The retrieval of water vapour at IMK/IAA has been improved since the work of Milz et al. (2005). Firstly, improved spectra have become available from offline level 1 reprocessing. Secondly, upgrades in the retrieval strategy have been implemented since then. This includes a different selection of spectral regions used for analysis, the so-called microwindows. Two microwindows (1594.450-1594.550 $\mathrm{cm}^{-1}, 1653.300-1653.400 \mathrm{~cm}^{-1}$ ) have been dropped from the list because they would require modeling of non-local thermodynamic equilibrium of both $\mathrm{H}_{2} \mathrm{O}$ and the interfering species $\mathrm{NO}_{2}$ which was added as a jointfit parameter. Furthermore, the altitude-dependent selection of microwindows has been altered to better exclude saturated spectral lines. From version H2O_V3O_13 on, the logarithm of water vapour volume mixing ratio (VMR) is retrieved instead of the VMR itself. In a log retrieval, the resolution affects relative rather than absolute changes in the atmospheric state, and the dependence on the atmospheric state thus is implicit and has not to be considered explicitly. This implies an 

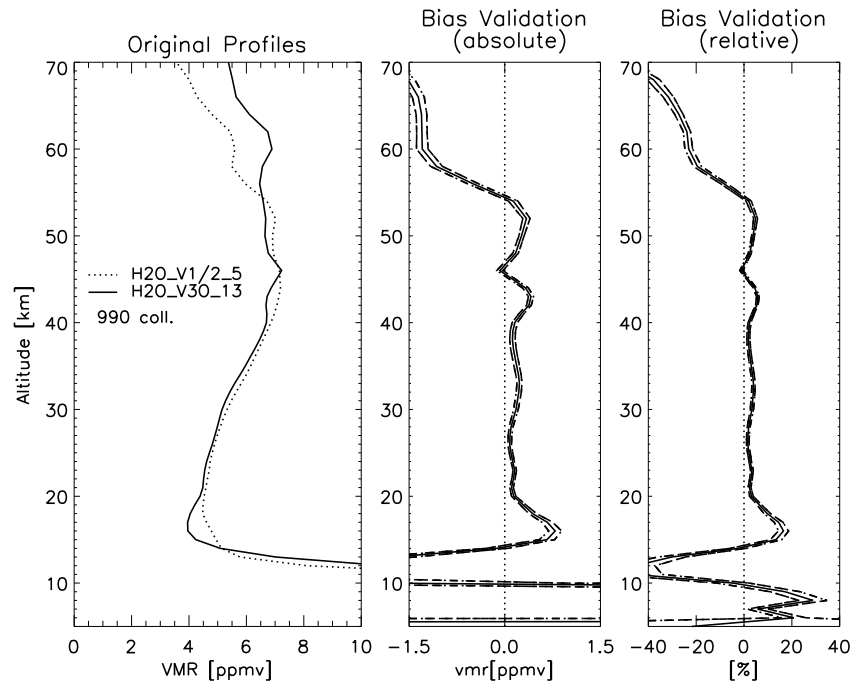

Fig. 1. Left panel: MIPAS H2O_V3O_13 (solid) and H2O_V1/2_5 (dotted) mean profiles. Middle panel: Absolute bias MIPAS (V1/2) - MIPAS (V3O) (solid) with with its uncertainty (dashes). Right panel: Relative bias MIPAS (V1/2) - MIPAS (V3O) (solid) with its uncertainty. The uncertainties in the middle and right panel are given in terms of two standard deviations of the mean (dashes).

altitude-dependent regularization of the VMR profile without requiring knowledge of the exact altitude of the the water vapour minimum (so-called hygropause (Kley et al., 1979)). This has finally led to an improved altitude resolution.

In Fig. 1 the mean differences between old (H2O_V1_5/H2O_V2_5) and new (H2O_V3O_V13) retrievals are shown for nearly 1000 individual profiles. The profiles used are globally distributed and differences in daytime and nighttime measurements were not considered. In the middle and upper stratosphere from about 20 to $55 \mathrm{~km}$ the results agree very well. The high bias of 3 to $5 \%$ of results obtained with H2O_V1/2_5 compared to H2O_V3O_13 reflects improvements as water vapour profiles obtained by H2O_V1/2_5 were found to be slightly biased high.

The difference in the lower stratosphere and tropopause region is significantly larger. This difference reflects the reduced regularization strength and therefore improved vertical resolution. The tropopause region with the hygropause is better resolved by the new retrieval approach. The altitude resolution of MIPAS H2O_V3O_13 profiles varies between $3.5-4.5 \mathrm{~km}$.

Differences between the versions of water vapour profiles above the stratopause are more pronounced. Here the old retrieval setup has a strong dry bias of up to $40 \%$. This is explained by non-local thermodynamic equilibrium emissions in some of the spectral regions selected in the new retrieval setup which were chosen because of their large sensitivity. However, The problem of non-local thermodynamic equilibrium emissions became evident only after the data
Table 1. Horizontal resolution in terms of full width at half maximum of the row of the horizontal averaging kernels and information displacement. A positive sign represents displacement towards the satellite.

\begin{tabular}{rrr}
\hline Altitude & $\begin{array}{r}\text { Horizontal } \\
\text { Resolution } \\
(\mathrm{km})\end{array}$ & $\begin{array}{r}\text { Information } \\
\text { Displacement } \\
(\mathrm{km})\end{array}$ \\
\hline 50. & 119. & 115. \\
40. & 220. & 45. \\
30. & 391. & -46. \\
20. & 360. & -38. \\
10. & 207. & -554. \\
\hline
\end{tabular}

set to be validated had already been analyzed. Data version H2O_V3O_V13 has been optimized to study processes in the upper troposphere and the stratosphere. Results retrieved at mesospheric altitudes are less reliable and should be used with particular care. This paper focuses on the water vapour in the stratosphere above the hygropause.

Most recent IMK data versions are also characterized in terms of horizontal smearing. In Table 1 we report the horizontal resolution in terms of the full width at half maximum (FWHM) of the relevant row of the horizontal averaging kernel matrix, and the displacement as the horizontal distance of the median of the row of the horizontal averaging kernel matrix and the nominal geolocation of the limb scan (von Clarmann et al., 2009).

\section{Retrieval}

For representation of the retrieval we use Rodgers (2000) terminology and notation:

$\hat{\boldsymbol{x}}=(\mathbf{I}-\mathbf{A}) \boldsymbol{x}_{\mathrm{a}}+\mathbf{A} \boldsymbol{x}+\mathbf{G} \epsilon$

Here $\hat{\boldsymbol{x}}=\log \mathrm{VMR}\left(\mathrm{H}_{2} \mathrm{O}\right)$ contains the logarithm of the vertical profile volume mixing ratios of $\mathrm{H}_{2} \mathrm{O}$. I is unity. $\boldsymbol{x}_{\mathrm{a}}$ contains the logarithm of the a priori profile and $\boldsymbol{x}$ the logarithm of the actual atmospheric profile. $\epsilon$ is the measurement noise. $\mathrm{G}$ is the gain matrix of the retrieval

$\mathbf{G}=\left(\mathbf{K}^{\mathbf{T}} \mathbf{S}_{\epsilon}^{-\mathbf{1}} \mathbf{K}+\mathbf{R}\right)^{-\mathbf{1}} \mathbf{K}^{\mathbf{T}} \mathbf{S}_{\epsilon}^{-1}$

and $\mathbf{A}$ is the averaging kernel matrix

$\mathbf{A}=\frac{d \hat{\boldsymbol{x}}}{d \boldsymbol{x}}=\mathbf{G K}$

where $\mathbf{K}$ is the Jacobian matrix, $\mathbf{S}_{\epsilon}$ the covariance matrix of the measurement (Rodgers, 2000). The regularization term $\mathbf{R}$ is a squared and scaled first order difference matrix (Milz et al., 2005). They describe the effect of limited resolution of the measurement and noise, respectively. 


\section{Comparison methodology}

\subsection{Coincidence criteria}

MIPAS data from the period September 2002 until March 2004 are used for this study. During this time MIPAS was operational with full spectral resolution. For comparison, data from ground based instruments and from instruments operating on various platforms are used. For ground based measurements and non-satellite platforms, the coincidence criterion is set to: a maximum of $6 \mathrm{~h}$ in time, a maximum of $800 \mathrm{~km}$ in distance with a maximum latitudinal difference of $4^{\circ}$ in order to obtain a sufficient amount of collocations. Measurements from satellite instruments were used with a more stringent coincidence criterion of $400 \mathrm{~km}$ in distance and a maximum latitudinal difference of $2^{\circ}$ which still provides sufficient coincidences for statistical analysis. The more stringent coincidence criterion with respect to latitudinal difference considers the fact that latitudinal variations are more pronounced than longitudinal ones. However, we are aware that dynamical features such as the position of the subtropical and polar jet streams introduce longitudinal variations in air masses.

\subsection{Strategy}

Terminology and formalism for this study are used as suggested by von Clarmann (2006). Bias is understood to be the mean deviation of the measurement from the truth. Since the truth is not known, the bias can also be expressed relative to an independent measurement and then is the mean deviation of the profiles. Precision is the reproducibility of a measurement, i.e. the expectation value of the bias-corrected root-mean squares difference between MIPAS profiles and the true water vapour profiles. Effects of finite resolution are considered (Rodgers and Connor, 2003), as described in Sect. 4.3. In a first step the bias between MIPAS and the validation data is determined, such that it can be corrected for in the second step which is precision validation.

The bias between two data sets from a sample of $K$ coincident pairs of measurements is

$\breve{\boldsymbol{b}}_{\text {diff }}=\frac{\sum_{k=1}^{K}\left(\hat{\boldsymbol{x}}_{\mathrm{MIPAS} ; k}-\hat{\boldsymbol{x}}_{\mathrm{ref} ; k}\right)}{K}$,

where $\hat{\boldsymbol{x}}_{\text {MIPAS }}$ are the water vapour profiles retrieved from MIPAS using the IMK/IAA retrieval processor, and $\hat{\boldsymbol{x}}_{\text {ref; } k}$ are the coincident profiles measured by the reference instrument. The statistical uncertainty of the bias $\breve{\sigma}_{\text {bias } ~}$, at altitude gridpoint $n$, is estimated as

$\breve{\sigma}_{\text {bias } ; n}=\sqrt{\frac{\sum_{k=1}^{K}\left(\hat{x}_{\text {MIPAS } ; n, k}-\hat{x}_{\text {ref } ; n, k}-\breve{b}_{\text {diff } ; n}\right)^{2}}{K(K-1)}}$,

In other words, $\breve{\sigma}_{\text {bias; } n}$ is estimated as the standard error of the difference between the two data sets. As pointed out by von
Clarmann (2006), this assessment does not need any error estimates of $\hat{\boldsymbol{x}}_{\text {MIPAS }}$ or $\hat{\boldsymbol{x}}_{\text {ref }}$. For percentage multiplicative bias estimates we use the percentage mean difference rather than the mean percentage difference.

With the bias between two instruments available, the precision at altitude gridpoint $n$ is validated by altitude-wise testing of the de-biased mean squares difference of the coincident measurements against the ex ante estimate of the variance of the difference in a $\chi^{2}$ sense:

$\left\langle\chi^{2}\right\rangle=\left\langle\frac{\sum_{k=1}^{K}\left(\hat{x}_{\mathrm{MIPAS} ; n ; k}-\hat{x}_{\mathrm{ref} ; n, k}-\breve{b}_{\text {diff } ; n}\right)^{2}}{\sigma_{\text {diff } ; n}^{2}}\right\rangle=K-1$.

\langle\rangle indicate the expectation value for $\chi^{2}$ which is the number of degrees of freedom. In this case this is $K-1$, since the bias which has been subtracted had been determined from the same set of data. Ideally, $\left(\sigma_{\text {diff; } n}^{2}\right)$ represents the combination of the ex ante estimates of the variance of random error sources affecting the comparison of the data sets, including the following additive components: the random error variance of MIPAS water vapour, the random error variance of the water vapour abundance measured with the reference instrument, the variance representing the expected difference due to less than perfect coincidence, and, if applicable, the smoothing error of the difference. Unfortunately estimates are not available for each error type. The MIPAS estimated random error includes measurement noise, as well as uncertainties of temperature, horizontal inhomogeneities of the temperature field, interfering species, and elevation of the line of sight. For MIPAS, the total random error is in the range of approximately 5 to $10 \%$ in the stratosphere. Around the tropopause the error can be larger (see e.g. Milz et al., 2005, Fig. 6 for mid-latitudinal conditions). The error sources considered for the reference instruments varies from instrument to instrument and is reported in the respective section. $\chi^{2}$ describes the validation of the assumed random errors provided with the data sets. For precision validation we use the so-called reduced $\chi^{2}$, which is $\chi^{2}$ divided by the degrees of freedom $(\operatorname{dgf})$, and of which the expectation value is one:

$\left\langle\chi_{\text {red. }}^{2}\right\rangle=\left\langle\frac{\chi^{2}}{d g f}\right\rangle=\left\langle\frac{\chi^{2}}{K-1}\right\rangle=1$

Again, due to the preceding bias correction, $d g f=K-1$. The $95 \%$ percentile of the $\chi^{2}$ distribution is used to assess the agreement of the de-biased data. The quantiles of the $\chi^{2}$ distribution as a function of the number of degrees of freedom are calculated with a standard program library for each altitude level. The number of measurements, and thus the degrees of freedom used for a certain altitude gridpoint depends on the altitude range covered by the individual limb scan. Especially at low altitudes cloud occurrence can exclude parts of a profile which is valid at higher altitudes. 


\subsection{Altitude resolution and a priori content}

For the retrieval of water vapour from MIPAS measurements the IMK/IAA retrieval processor uses a priori information. The same is true for some of the validation instruments. In order to avoid artefacts in the differences between $\mathrm{H}_{2} \mathrm{O}$ profiles, we transfer the profiles to a common a priori whenever all required data (averaging kernels, a priori profiles) of the comparison data set are available (Rodgers, 2000).

$$
\begin{aligned}
\hat{\mathbf{x}}_{\mathbf{n}}= & \mathbf{x}_{a, \mathrm{val}}+\mathbf{A}_{\mathrm{val}}\left(\hat{\mathbf{x}}_{\mathrm{val}}-\mathbf{x}_{a, \mathrm{val}}\right)+ \\
& +\left(\mathbf{A}_{\mathrm{val}}-\mathbf{I}\right)\left(\mathbf{x}_{a, \mathrm{val}}-\mathbf{x}_{a, \mathrm{ref}}\right)
\end{aligned}
$$

where $\hat{\mathbf{x}}_{\mathbf{n}}$ is the profile $\hat{\mathbf{x}}_{\mathrm{val}}$ transferred to the a priori $\mathbf{x}_{a, \text { ref }}$ of the reference instrument. $\mathbf{x}_{a, \mathrm{val}}$ is the a priori profile of the measurement to be validated and $\mathbf{A}_{\mathrm{val}}$ is the averaging kernel matrix of the measurement to be validated. Even after this transformation, the profiles are not yet directly comparable, because they still contain a different amount of a priori information and the altitude resolution of the profiles still can be different. Further, Eq. (8) is a linear transformation but the profile differences may be larger than the range of applicability of linear theory. The averaging kernel matrix $\mathbf{A}_{\text {val }}$ is modified during the iteration process. Here the averaging kernel calculated for the last iteration is used for MIPAS. Rodgers (2000) suggests to evaluate the smoothing error of the difference profile in terms of covariance matrix $\mathbf{S}_{\text {smooth }}$. Since the required climatological covariance is difficult to obtain and the averaging kernel is not available for most of the reference instruments, we did not apply the according equation. Instead we classify the independent measurements as follows:

(a) HALOE, ACE-FTS, ILAS-II, POAM III and MIPAS$B$ are also satellite-borne limb sounders which have a similar but slightly better vertical resolution than MIPAS. In this case we compare the profiles directly at altitudes where the profiles are quite smooth such that they can be well resolved by both instruments. For this direct comparison, we exclude the hygropause region, because differences at sharp structures in the water vapour profile are most probably an artefact due to the different altitude resolution. In addition comparisons of MIPAS to the profile of the comparison instrument smoothed by the MIPAS averaging kernels are studied in order to better understand the effect of different altitude resolution.

(b) The microwave radiometers MIAWARA and AMSOS have much poorer altitude resolution than MIPAS. For these comparisons the higher resolved MIPAS profile is brought to the resolution of the low resolution instrument by the following equation (Rodgers and Connor, 2003):

$\hat{\mathbf{x}}_{\mathrm{hr}, \text { degraded }}=\mathbf{x}_{\mathrm{a}, \mathrm{lr}}+\mathbf{A}_{\mathrm{lr}, \mathrm{hr}}\left(\hat{\mathbf{x}}_{\mathrm{hr}}-\mathbf{x}_{\mathrm{a}, \mathrm{lr} \text {, interpolated }}\right)$.

$\hat{\mathbf{x}}_{\mathrm{hr}}$ and $\hat{\mathbf{x}}_{\mathrm{hr} \text {,degraded }}$ are the original and degraded high resolution profiles, respectively. $\mathbf{x}_{\mathrm{a}, \mathrm{lr}}$ is the a priori profile of the low resolution measurement, and $\mathbf{x}_{\mathrm{a}, \text { lr } \text {,interpolated }}$ is the a priori profile of the low resolution measurement interpolated to the vertical grid of the high resolution profiles. $\mathbf{A}_{\mathrm{lr}, \mathrm{hr}}$ is the
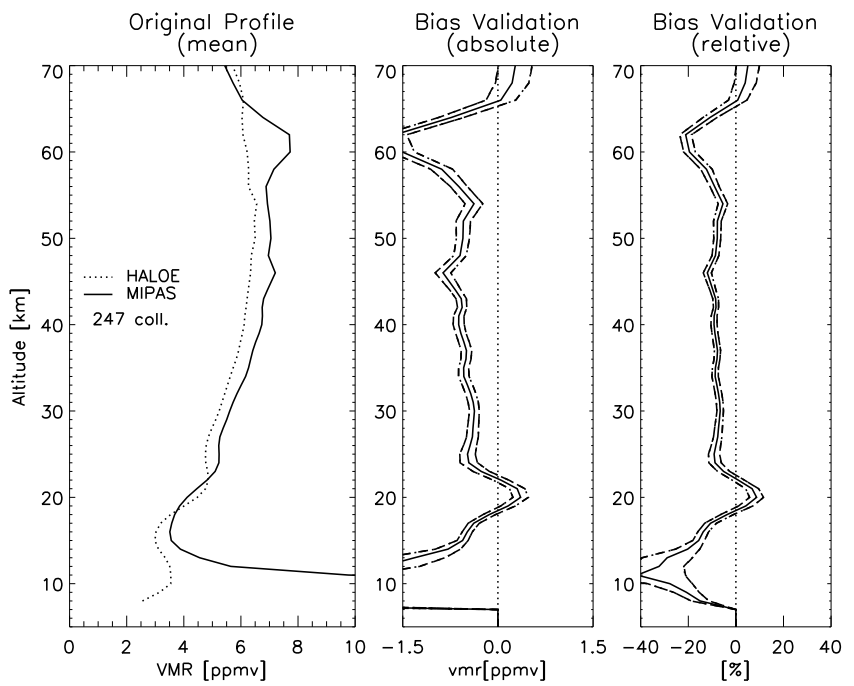

Fig. 2. Left: Mean original profiles of MIPAS (solid) and HALOE (dotted) for coincidences of MIPAS and HALOE sunrise measurements. Center: Absolute bias HALOE - MIPAS (solid) with standard deviation of the mean ( $2 \sigma$-values, dashes). Right: Relative bias HALOE - MIPAS (solid) with standard deviation of the mean ( $2 \sigma$-values, dashes).

related averaging kernel matrix which has been modified to enable multiplication of the low resolution averaging kernel with the high resolved measurement $\hat{\mathbf{x}}_{\mathrm{hr}}$. The rows of the matrix $\mathbf{A}_{\text {lr }}$ were linearly interpolated to the altitude grid representing the high resolved profile.

The retrieval error covariance matrix $\mathbf{S}$ of the high resolution measurement is transformed accordingly:

$\mathbf{S}_{\text {degraded }}=\mathbf{A}_{\mathrm{lr}}^{T} \mathbf{S} \mathbf{A}_{\mathrm{lr}}$

(c) The in situ sensors FLASH-B, NOAA frostpoint hygrometer and FISH have a much better altitude resolution than MIPAS. For these comparisons, the in situ measurements are degraded to the altitude resolution of MIPAS, using Eq. (9).

\section{Results and discussion}

\subsection{Comparison with satellite borne remote sensing instruments}

\subsubsection{HALOE}

The Halogen Occultation Experiment (HALOE) on board the Upper Atmosphere Research Satellite (UARS) was launched in 1991 and was operated from 1992 to 2005 . HALOE was operating in solar occultation geometry and measured water vapour profiles during sunrise and sunset events relative to the satellite (Russell III et al., 1993). For the coincidences considered in this study, sunrise measurements occur 


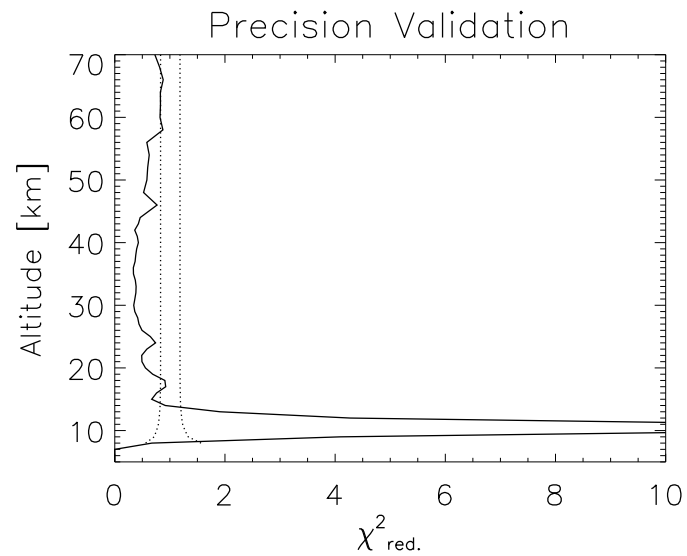

Fig. 3. $\chi^{2}$ analysis for precision validation for MIPAS and HALOE sunrise measurements. Dotted lines: $95 \%$ percentiles of $\chi_{\text {red. }}^{2}$ distribution.

mostly in the Northern Hemisphere, sunset events mostly in the Southern Hemisphere. The altitude resolution of HALOE $\mathrm{H}_{2} \mathrm{O}$ profiles is $2.3 \mathrm{~km}$. This allows direct comparison of profiles throughout the stratosphere except near the hygropause.

For HALOE sunrise measurements, a total of 247 collocated profiles from MIPAS and HALOE was found. Below $16 \mathrm{~km}$ the agreement of both instruments is comparatively poor because both instruments resolve the hygropause differently, and information on the highly variable tropospheric water vapour content is mapped differently into the altitude range under investigation. As a consequence, we restrict our discussion to altitudes which can be clearly assigned to the stratosphere. As most coincidences are located at midand high latitudes, the hygropause is assumed to be below $15 \mathrm{~km}$; thus only results at $16 \mathrm{~km}$ and higher are compared. In the stratosphere, the mean profiles of both instruments agree generally well and reflect similar vertical structures. In the stratosphere between about 23 and $55 \mathrm{~km}$ altitude MIPAS has a positive bias of approx. $0.5 \mathrm{ppmv}$ or $10 \%$. Around $45 \mathrm{~km}$ the bias is slightly larger with values up to $0.7 \mathrm{ppmv}$ (see Fig. 2). Below $23 \mathrm{~km}$ different structures in the averaged profiles do not show a clear bias. The differences here are determined by the different reproduction of the increase in $\mathrm{H}_{2} \mathrm{O}$ directly above the tropopause region introduced by the different height resolution of the instruments. The $\chi^{2}$ analysis was performed using the random part of the total error for HALOE and is shown in Fig. 3. According to Harries et al. (1996) and SPARC (2000) the random part of the total error is in the range of 14 to $27 \%$ in the stratosphere with the smallest errors in the middle to upper stratosphere.

The dotted lines show the $95 \%$ confidence interval of the $\chi_{\text {red. }}^{2}$ distribution function. For all altitudes between 19 and $57 \mathrm{~km}$ the $\chi_{\text {red. }}^{2}$ values are below the lower confidence limit. This indicates that the assumed errors are larger than the actual precision. Between 14 and $19 \mathrm{~km}$ and above $57 \mathrm{~km}$ the
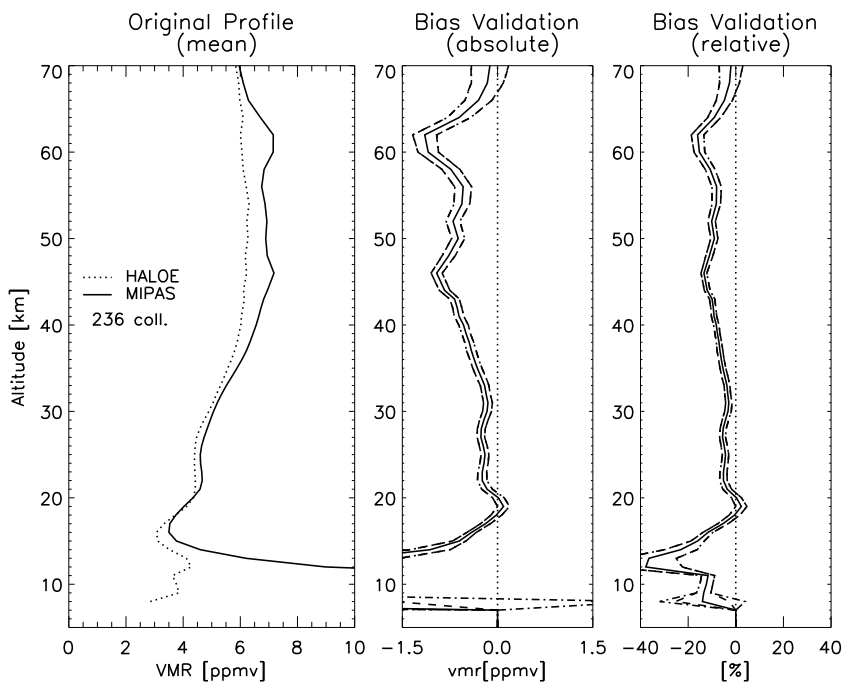

Fig. 4. As Fig. 2 but for HALOE sunset measurements.

$\chi_{\text {red. }}^{2}$ is close to the lower limit or within the limits. Here the assumed errors seem to be realistic. Only at altitudes below $14 \mathrm{~km}$ the $\chi_{\text {red. }}^{2}$ values exceed the upper confidence limit indicating that the assumed errors of the difference profiles may be too optimistic. However, this is the tropopause region with its large natural variability which is not discussed in this study. The HALOE random error estimates contain measurement noise, tracker noise, $\mathrm{CH}_{4}$ random error, and aerosol correction uncertainty.

Comparison with HALOE sunset measurements, provided a total of 236 collocated profiles from both instruments meeting the coincidence criteria. As described above, only altitudes clearly attributed to the stratosphere are relevant. As was found for the HALOE sunrise measurements, MIPAS $\mathrm{H}_{2} \mathrm{O}$ is biased wet compared to HALOE also for the sunset measurements (Fig. 4) by about 0.5 ppmv or $10 \%$, respectively. Around $20 \mathrm{~km}$ the agreement is better than for sunrise measurements. The $\chi^{2}$ analysis shown in Fig. 5 indicates overestimation of the combined random error at all altitudes between 15 and $70 \mathrm{~km}$.

\subsubsection{ACE-FTS}

The Fourier Transform Spectrometer (FTS) on board the Atmospheric Chemistry Experiment (ACE) satellite (ACEFTS) was launched on 12 August 2003 orbiting at ca. $650 \mathrm{~km}$ altitude with an inclination of ca. $74^{\circ}$ (Bernath et al., 2005). Since February 2004, ACE-FTS has measured in solar occultation mode. Among the measured species are vertical profiles of water vapour.

Here we consider only measurements recorded during satellite's sunrise events. The vertical resolution of retrieved water vapour profiles is assumed to be in the range of $3-4 \mathrm{~km}$ for ACE-FTS (Boone et al., 2005) which is similar to that of 


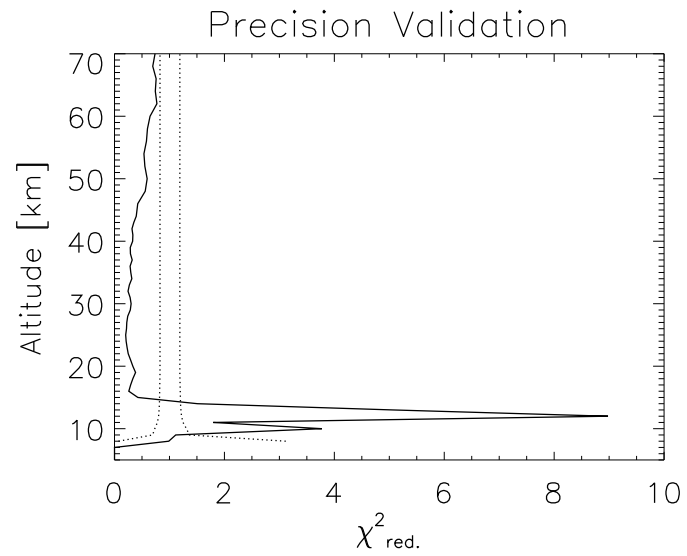

Fig. 5. As Fig. 3 but for HALOE sunset measurements.
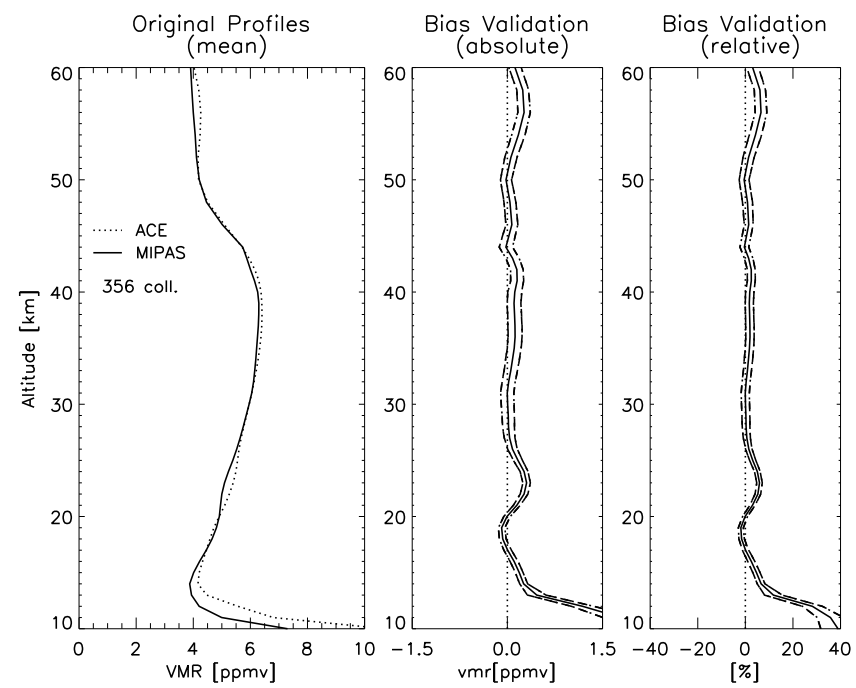

Fig. 6. Bias between MIPAS and ACE-FTS; for details, see Fig. 2.

the MIPAS measurements. Therefore the approach of direct comparison of profiles was chosen.

Similar to HALOE sunrise measurements ACE-FTS profiles are mainly measured at northern mid-latitudes and high latitudes. Figure 6 shows the mean profiles and bias validation of 356 collocated measurements from February/March 2004, mostly during Arctic winter. The coincidence period was limited by the switch-off of MIPAS due to an instrument failure at the end of March 2004. Contrary to HALOE, ACE-FTS measures higher water vapour than MIPAS below $15 \mathrm{~km}$. Strong discrepancies at these altitudes hint at the general problems in remotely sounding the hygropause in limb geometry. Between 16 and $60 \mathrm{~km}$, ACE-FTS and MIPAS water vapour profiles are in good agreement. The differences $(0.3$ ppmv or $5 \%)$ are not significant except for the range between 21 and $25 \mathrm{~km}$, where the bias is slightly larger than its standard error. The feature around $50 \mathrm{~km}$ is observed by both instruments.

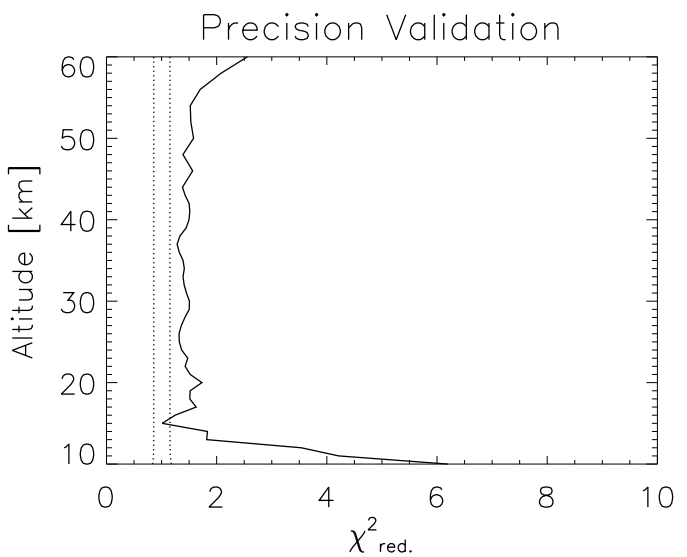

Fig. 7. $\chi^{2}$ analysis for precision validation for MIPAS and ACEFTS water vapour; for details, see Fig. 3.

In Fig. 7 the $\chi^{2}$ analysis for the comparison of ACE-FTS is shown. Generally the calculated $\chi_{\text {red. }}^{2}$ values are found to be larger than the $95 \%$ confidence limits of the $\chi_{\text {red. }}^{2}$. distribution, most probably because the ACE error budget includes only measurement noise with no further types of random errors (Boone et al., 2005). For the considered altitudes above approximately $15 \mathrm{~km}$ the noise is in the range of 1 to $3 \%$. Beyond this, the differences due to less than perfect coincidences will contribute to the differences, particularly if there is large variability of the atmospheric state.

These results confirm the work of Carleer et al. (2008) who compared MIPAS water vapour profiles version H2O_V3O_13 to ACE-FTS. These authors found a mean multiplicative bias of $3.3 \%$ of ACE-FTS with respect to MIPAS in the altitude range 14 to $68 \mathrm{~km}$. Both instruments agree very well within their respective standard deviations (5-15\% for ACE-FTS and 15\% for MIPAS).

\subsubsection{ILAS-II}

The Improved Limb Atmospheric Spectrometer-II (ILAS-II) was launched on the Advanced Earth Observing SatelliteII (ADEOS-II) on 14 December 2002. ADEOS-II had a sun-synchronous orbit with $98.7^{\circ}$ inclination at an average altitude of $803 \mathrm{~km}$. ILAS-II measured from January 2003 to October 2003 (Nakajima et al., 2006). It used the same measurement principle as HALOE and ACE-FTS, measuring in solar occultation, during sunrise and sunset relative to the satellite. From April to October 2003 ILAS-II measured continuously with 14 sunrise and sunset occultations per day, respectively, using four channels, three in the infrared $\left(778-782 \mathrm{~cm}^{-1}, 850-1610 \mathrm{~cm}^{-1}, 1754-3333 \mathrm{~cm}^{-1}\right)$ and one in the visible. $\left(12755-13280 \mathrm{~cm}^{-1}\right)$. The vertical profiles discussed here were obtained using the infrared channel covering the range from 850 to $1610 \mathrm{~cm}^{-1}$ and are version 2 . The altitude range from 15 to $55 \mathrm{~km}$ is covered 

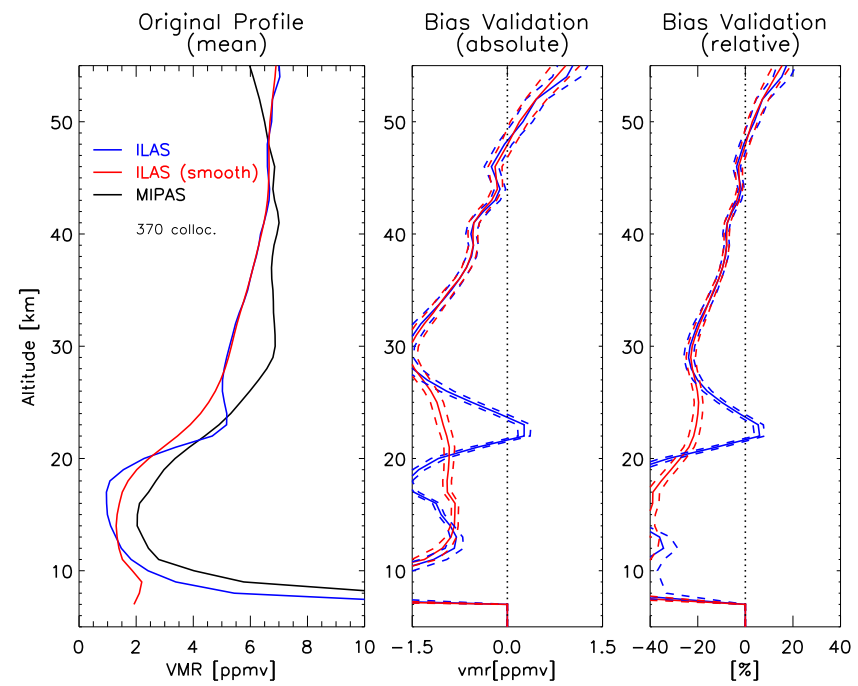

Fig. 8. Bias between MIPAS and ILAS-II Southern hemispheric water vapour measurements (satellite sunset). Blue: ILAS-II original profiles. Red: ILAS-II water vapour measurements smoothed with MIPAS averaging kernels. For details, see Fig. 2.

with an instantaneous FOV of $1 \mathrm{~km}$ in the vertical and $13 \mathrm{~km}$ in the horizontal. For this altitude range the total error is between 3 and $20 \%$ with a minimum around $30 \mathrm{~km}$ and largest uncertainties towards the stratopause and further increasing above. Water vapour profiles measured during sunrise are located in the Northern Hemisphere while sunset measurements are in the Southern Hemisphere. The profiles were retrieved using an onion peeling algorithm (Yokota et al., 2002). ILAS-II water vapour products have been compared to MIPAS H2O_V3O_11 profiles by Griesfeller et al. (2008). Due to the changes in the retrieval setup from version H2O_V3O_11 to H2O_V3O_13 the comparison is redone. Water vapour profiles measured during sunrise appear to have different characteristics than those measured during sunset (Griesfeller et al., 2008). Therefore measurements from each hemisphere are compared separately. The vertical resolution of ILAS-II $\mathrm{H}_{2} \mathrm{O}$ profiles is 1.3 to $2.9 \mathrm{~km}$ (Nakajima et al., 2006) which is finer than that of MIPAS but still close enough to justify direct comparison of profiles all over the stratosphere except near the hygropause. This study compares MIPAS measurements both to the original ILASII profiles and the ILAS-II profiles smoothed by the MIPAS averaging kernels.

The majority of the 370 collocated measurements of MIPAS and ILAS-II sunset scans in the Southern Hemisphere are located inside the polar vortex as most ILAS-II measurements were taken during Austral winter and spring at high latitudes (Griesfeller et al., 2008). In Fig. 8 the averaged profiles (ILAS: blue, MIPAS: black) and bias profiles (blue) of the collocated measurements are shown. The averaged profiles of both instruments reveal comparatively dry air masses

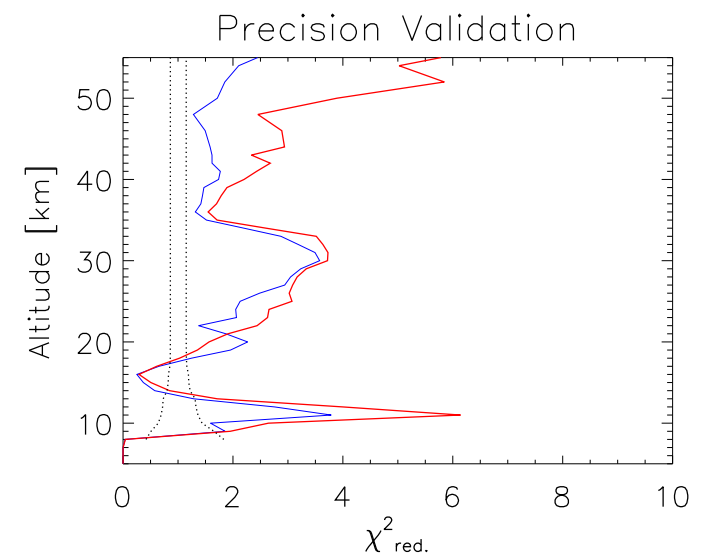

Fig. 9. $\chi^{2}$ analysis for precision validation for MIPAS and ILAS-II Southern hemispheric water vapour measurements (satellite sunset). Blue: ILAS-II original profiles. Red: ILAS-II profiles smoothed with MIPAS averaging kernels. For details, see Fig. 3.

in the lower stratosphere inside the polar vortex which are a result of the dehydration processes related to the formation of PSC and subsequent fall out of growing ice particles during Austral winter. Above approximately $25 \mathrm{~km}$ the profiles are shaped as expected for unperturbed conditions. However, the profiles are quite different at altitudes affected by dehydration as well as at altitudes above the dehydrated air masses. Above $25 \mathrm{~km}$ MIPAS measures up to $20 \%$ more $\mathrm{H}_{2} \mathrm{O}$. Above $45 \mathrm{~km}$ MIPAS tends to measure up to $20 \%$ less $\mathrm{H}_{2} \mathrm{O}$. The $\mathrm{H}_{2} \mathrm{O}$ maximum in terms of VMR is around $40 \mathrm{~km}$ in the MIPAS profiles and around $55 \mathrm{~km}$ in the ILAS-II profiles.

Below $25 \mathrm{~km}$ ILAS-II shows a distinctive drop in observed water vapour VMR down to values of about $1 \mathrm{ppmv}$ at $18 \mathrm{~km}$. The decrease in the MIPAS mean profile is weaker, reaching values around $1.5 \mathrm{ppmv}$ at $15 \mathrm{~km}$. Here the different vertical resolution may lead to different profile shapes. The MIPAS vertical resolution is poorer here since at low temperatures inside the polar vortex and its remnants the measurements of thermal emission are less sensitive, implying a stronger effect of the constraint applied to the retrieval. Below $25 \mathrm{~km}$ MIPAS is wetter by up to $1.5 \mathrm{ppmv}$ at $18 \mathrm{~km}$, which exceeds $50 \%$ in relative terms due to the low absolute values.

Generally, the calculated $\chi_{\text {red. }}^{2}$ values are larger than the upper confidence limit (see Fig. 9, blue line). Only around $17 \mathrm{~km}$ are the $\chi_{\text {red. }}^{2}$ values smaller dropping below the lower confidence limit.

In order to investigate the effect of the different vertical resolutions, also a comparison of MIPAS profiles to ILASII profiles smoothed by MIPAS averaging kernels according to Eq. (9) has been performed. The comparison of the averaged profiles for MIPAS and ILAS-II smoothed by application of MIPAS averaging kernels are shown in Fig. 8 with red lines for the smoothed ILAS-II profiles. Above $27 \mathrm{~km}$ the mean differences are quite similar to those obtained from 

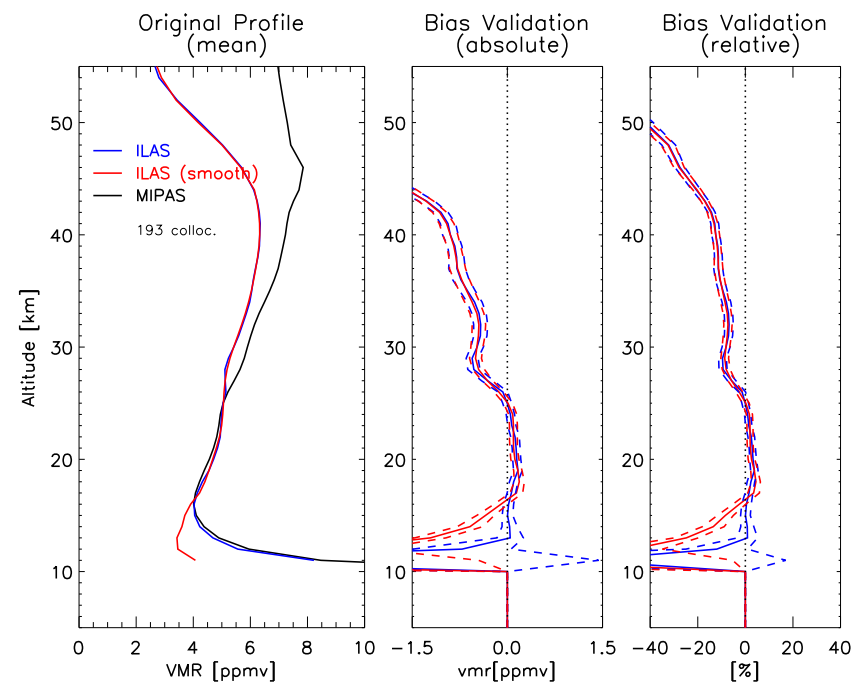

Fig. 10. Bias between MIPAS and ILAS-II Northern hemispheric water vapour measurements (satellite sunrise). Blue: ILAS-II original profiles. Red: ILAS-II water vapour measurements, smoothed with MIPAS averaging kernels. For details, see Fig. 2.

the comparison to the original ILAS-II profiles. Here the atmospheric structures appear to have vertical extents large enough to be resolved also by MIPAS. Below $23 \mathrm{~km}$, the sharp dehydration signal of the air masses visible in the original ILAS-II data is smoothed. The profile shapes of MIPAS and ILAS-II are now similar, while MIPAS measures about 1 ppmv more $\mathrm{H}_{2} \mathrm{O}$ throughout the altitude range from 10 to $40 \mathrm{~km}$. The maximal difference of $1.5 \mathrm{ppmv}$ is found at around $30 \mathrm{~km}$. Also for this comparison the $\chi^{2}$-test suggests underestimated random errors or disregarded error sources for one of the instruments compared or due to less than perfect co-incidences (Fig. 9, red line). Either the error estimates are not representative for the very cold polar vortex which is characterized by large horizontal gradients of atmospheric state variables, and which make limb retrievals a challenge, or the large horizontal gradients imply typically large profile difference because of insufficient coincidence of the measurements.

Most (193) measurements of ILAS-II obtained during satellite sunrise were recorded in the Northern Hemisphere. Above $40 \mathrm{~km}$ MIPAS has a large positive bias with differences of up to 2 ppmv at $50 \mathrm{~km}$ (Fig. 10, blue line). As discussed above, the MIPAS results at altitudes above approximately $53 \mathrm{~km}$ are affected by non-LTE effects, and the limited vertical resolution may map enhanced values from high altitudes down to the upper stratosphere. Between $15 \mathrm{~km}$ and $26 \mathrm{~km}$ both instruments agree very well with a relative bias below $3 \%$, which lacks significance. Around $30 \mathrm{~km}$, MIPAS measures more water vapour by up to $10 \%$ or $0.5 \mathrm{ppmv}$, respectively. Below $15 \mathrm{~km}$ the mean difference is huge $(-15 \%$ to $+20 \%$ ) but, in view of the uncertainty of the bias, not significant.

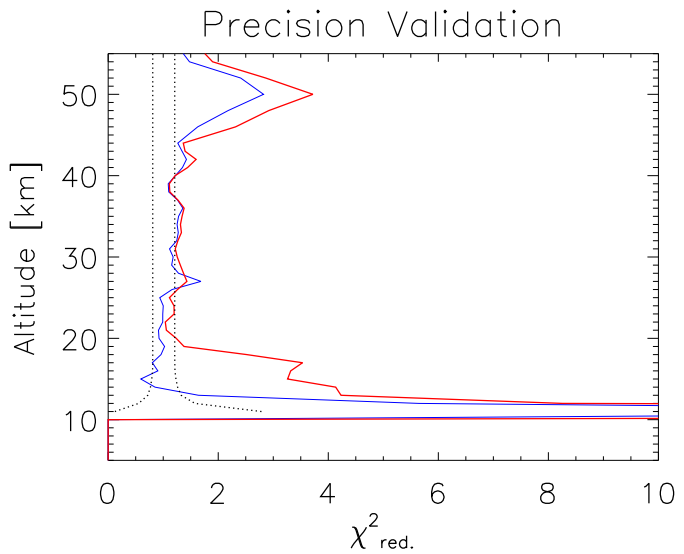

Fig. 11. $\chi^{2}$ analysis for precision validation for MIPAS and ILASII Northern hemispheric water vapour measurements (satellite sunrise). Blue: ILAS-II original profiles. Red: ILAS-II profiles smoothed with MIPAS averaging kernels. For details, see Fig. 3.

The precision validation in Fig. 11 (blue line) indicates that the ex ante error estimates have been quite reliable between 15 and $26 \mathrm{~km}$. Here the $\chi_{\text {red. }}^{2}$-values are well within the estimated confidence limits. Contrary to the satellite instruments discussed in the previous sections, the ILAS-II error budget includes, besides the retrieval noise, also the propagation of temperature errors and errors due to uncertain abundances of interfering species. This might explain why the $\chi_{\text {red. }}^{2}$-values of this comparison are much smaller. The fact that the $\chi_{\text {red. }}^{2}$-values found for the Northern Hemisphere are much smaller than those found for the Southern Hemisphere is attributed to the inappropriate representation of the particular atmospheric condition of polar vortex air by the global error estimates. If there was a general problem with the MIPAS or ILAS-II error estimates, also the Northern hemispheric $\chi_{\text {red. }}^{2}$-values would be larger. Below $15 \mathrm{~km}$ the calculated $\chi_{\text {red. }}^{2}$ exceeds the confidence limit of a $\chi_{\text {red. }}^{2}$-distribution also for the Northern Hemisphere. Possible explanations are less than perfect coincidences in an altitude range where large horizontal variability is expected, and the different capability of the instruments to resolve the hygropause. In order to test the latter explanation, again a comparison of MIPAS profiles to ILAS-II profiles smoothed by the MIPAS averaging kernels has been performed. The mean differences (Fig. 10, red lines) remain quite similar except for the hygropause region, where this approach suffers from border effects. The calcu-

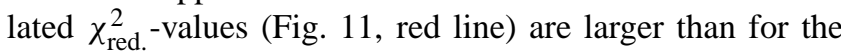
direct comparison, suggesting that the smoothing approach chosen, which assumes that ILAS-II is an ideal instrument with infinite resolving power, might not always be appropriate, particularly not near the hygropause region.

Griesfeller et al. (2008) used for their comparison IMKIAA water vapour profiles of version $\mathrm{H}_{2} \mathrm{O}$-V3O_11. For the Northern Hemisphere measurements, the agreement between 

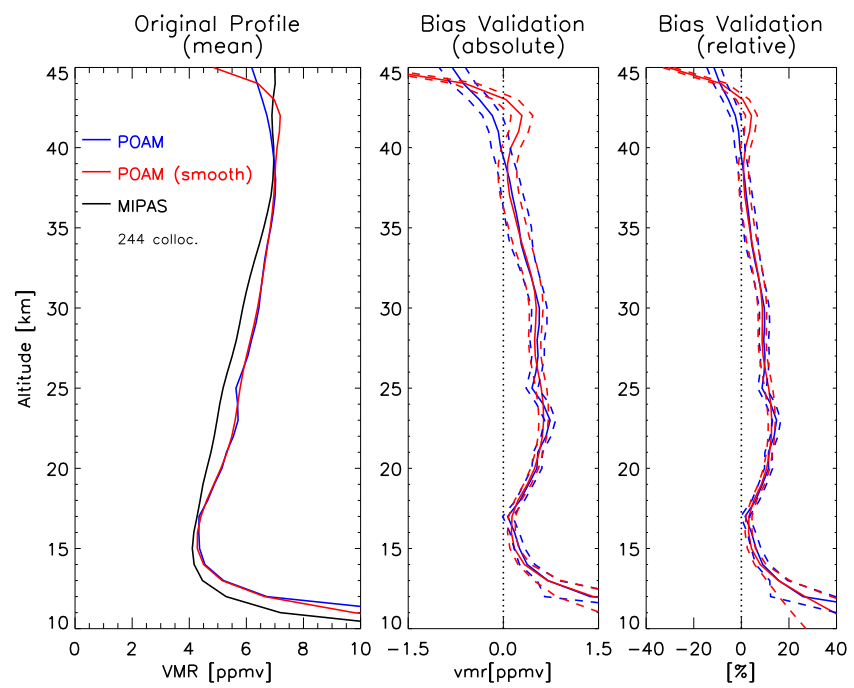

Fig. 12. Bias between MIPAS and POAM III Northern hemispheric water vapour measurements. Blue: POAM III original profiles. Red: POAM III profiles smoothed with MIPAS averaging kernels. For details, see Fig. 2.

15 and $27 \mathrm{~km}$ is very good in both studies. For altitudes between 30 and $40 \mathrm{~km} \mathrm{H2O}$-V3O_13 has a slightly larger wet bias of 10 to $15 \%$ compared to 5 to $10 \%$ for H2O_V3O_11. For the Southern Hemisphere measurements, the discrepancies between ILAS-II and MIPAS were quite large. The biases are at all altitudes similar for both versions of the IMK/IAA water vapour.

\subsubsection{POAM III}

The Polar Ozone and Aerosol Measurement III (POAM III) instrument is situated on the satellite SPOT-4 which was launched in spring 1998 using a sun-synchronous orbit with an $98.7^{\circ}$ inclination at $833 \mathrm{~km}$ altitude. POAM III operates, similar to HALOE, ACE-FTS, and ILAS-II, in solar occultation but unlike the aforementioned instruments the spectral channels of POAM III cover the visible and near infrared from 354 to $1018 \mathrm{~nm}$. The two channels used for water vapour retrievals are located at $922.4 \mathrm{~nm}$ and $935.9 \mathrm{~nm}$, respectively. POAM III records 14 sunrise and 14 sunset measurements per day. The altitude range covered for water vapour is 5 to $45 \mathrm{~km}$. Sunset measurements relative to the instruments are located in the Southern Hemisphere $\left(63^{\circ}\right.$ to $88^{\circ} \mathrm{S}$ ) and sunrise measurements are confined to Northern Hemisphere $\left(55^{\circ}\right.$ to $\left.71^{\circ} \mathrm{N}\right)$. However, Northern Hemisphere measurements correspond to local sunset (Lucke et al., 1999; Lumpe et al., 2006).

The vertical resolution of POAM III is $1-1.5 \mathrm{~km}$ between 10 and $30 \mathrm{~km}, 3 \mathrm{~km}$ at $40 \mathrm{~km}$ and $5 \mathrm{~km}$ at $45 \mathrm{~km}$ (Lumpe et al., 2006), which is slightly better than that of MIPAS. Both direct comparison of MIPAS and POAM III $\mathrm{H}_{2} \mathrm{O}$ pro-

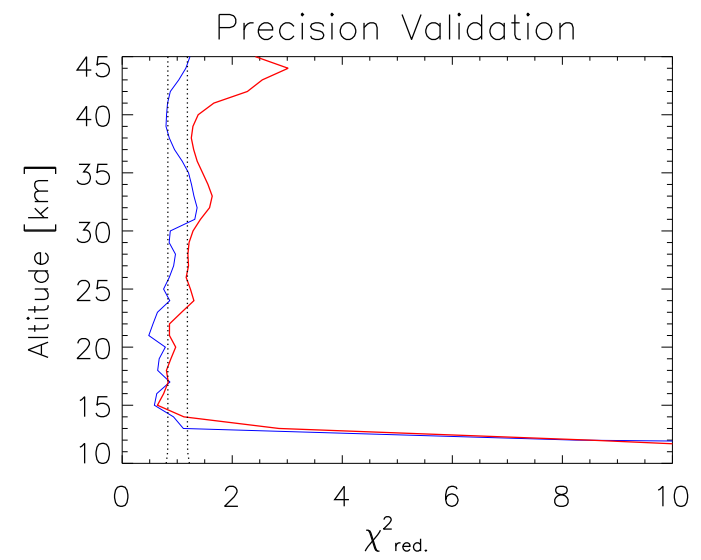

Fig. 13. $\chi^{2}$ analysis for precision validation for MIPAS and POAM III Northern hemispheric water vapour measurements. Blue: POAM III original profiles. Red: POAM III profiles smoothed with MIPAS averaging kernels. For details, see Fig. 3.

files and comparison of original MIPAS profiles with POAM III profiles smoothed with the MIPAS averaging kernel were performed.

Comparisons of POAM III measurements with HALOE and SAGE II (Stratospheric Aerosol and Gas Experiment II) indicate that measurements on the Southern Hemisphere show a positive bias of 5 to $10 \%$ compared to POAM III measurements from the Northern Hemisphere (Lumpe et al., 2006). Therefore measurements in the different hemispheres are treated separately.

Figure 12 shows the bias determination between MIPAS and original POAM III sunrise measurements (blue lines). For this comparison a set of 244 suitable coincidences was used. For altitudes above $42 \mathrm{~km}$ MIPAS $\mathrm{H}_{2} \mathrm{O}$ is larger by up to $1 \mathrm{ppmv}(+15 \%)$. Below $39 \mathrm{~km}$ the sign of the bias flips and MIPAS reports less $\mathrm{H}_{2} \mathrm{O}$. The value of this negative bias varies with altitude as different structures appear in the averaged profiles of both instruments. The maximum mean difference is approximately $0.75 \mathrm{ppmv}(15 \%)$ at around $23 \mathrm{~km}$, related to a prominent structure in the POAM III mean profile. A minimum in the mean difference occurs at $17 \mathrm{~km}$ with less than $0.1 \mathrm{ppmv}(3 \%)$ and rapidly increasing for altitudes below.

The corresponding $\chi^{2}$ test is shown in Fig. 13 (blue line). The $\chi_{\text {red. }}^{2}$ was calculated with the total random error for POAM III provided with the data. The error range is between 4 and 7\% (Lumpe et al., 2006). For altitudes below $13 \mathrm{~km}$ the calculated $\chi_{\text {red. }}^{2}$ values exceed the upper confidence limit. This is explained by the different altitude resolution, which is particularly important near the hygropause. Above $13 \mathrm{~km}$ the values are in the range of the confidence limits. However, below $30 \mathrm{~km}$ the values tend to be slightly smaller than the lower confidence limit, indicating that the combined errors for POAM III and MIPAS are too pessimistic in this altitude 

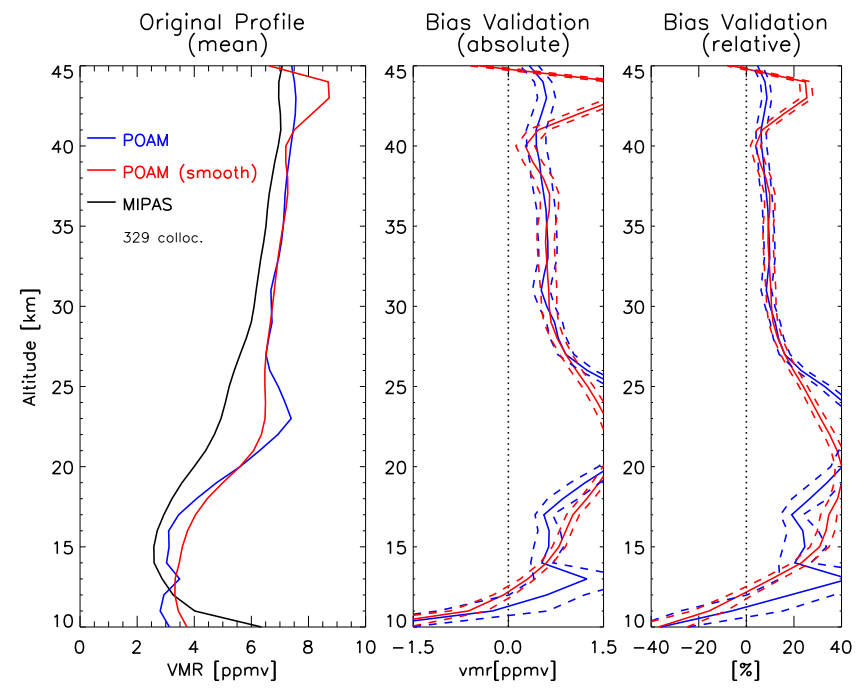

Fig. 14. Bias between MIPAS and POAM III Southern hemispheric water vapour measurements. Blue: POAM III original profiles. Red: POAM III profiles smoothed with MIPAS averaging kernels. For details, see Fig. 2.

range. Between $30 \mathrm{~km}$ and $36 \mathrm{~km}$ the $\chi_{\text {red. }}^{2}$ values are slightly larger than the upper confidence limit, and around $40 \mathrm{~km}$ they are too low again.

In Fig. 12 red lines show the bias determination for the same set of collocated Northern hemispheric POAM III profiles after smoothing using the MIPAS averaging kernels and a priori profiles before averaging. The general shape of the bias profile is similar to the one described for the original POAM III profiles. However, some of the structures visible for the untreated profiles (blue) have been smoothed out. The prominent bump is weaker. The maximum difference of $0.7 \mathrm{ppmv}$ or $15 \%$ is found at $23 \mathrm{~km}$. The differences above ca. $40 \mathrm{~km}$ and below $15 \mathrm{~km}$ are not discussed since the nominal altitude range of POAM III $\mathrm{H}_{2} \mathrm{O}$ is $10-45 \mathrm{~km}$, and smoothing with the MIPAS averaging kernels introduces a boundary effect in a sense that possible erroneous profile values from outside the POAM III nominal altitude range are mapped into the altitude range.

The precision validation for smoothed Northern Hemisphere measurements in Fig. 13 (red line) shows similar vertical distributions as for the original profiles. Between 30 and $43 \mathrm{~km}$ the $\chi_{\text {red. }}^{2}$ values are inside the confidence limits. Below $30 \mathrm{~km}$ the values are smaller than the lower confidence limit.

For POAM III measurements of water vapour during satellite sunset a total of 329 coincidences was used. The bias and precision determination for POAM III Southern Hemisphere measurements are displayed with blue lines in Figs. 14 and 15. At all altitudes above $12 \mathrm{~km}$ POAM III observes larger $\mathrm{H}_{2} \mathrm{O}$ abundances than MIPAS. Above $26 \mathrm{~km}$ the estimated bias between MIPAS and POAM III exhibits a similar alti-

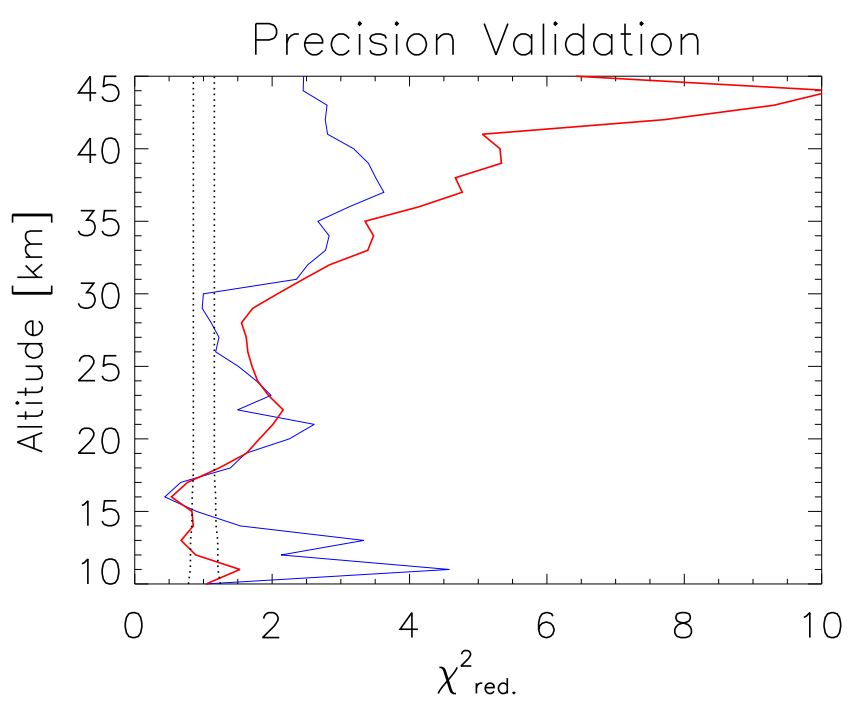

Fig. 15. $\chi^{2}$ analysis for precision validation for MIPAS and POAM III Southern hemispheric water vapour measurements. Blue: POAM III original profiles. Red: POAM III profiles smoothed with MIPAS averaging kernels. For details, see Fig. 3.

tude distribution as for Northern Hemisphere measurements. As described by Lumpe et al. (2006), the values of the averaged POAM III measurements from the Southern Hemisphere are larger at all altitudes introducing a positive bias of 5 to $10 \%$ compared to the water vapour profile from Northern Hemisphere measurements by POAM III. However, between 20 and $26 \mathrm{~km}$, the averaged POAM III measurements reveal a strong maximum with values up to 8 ppmv leading to maximum difference of up to $2.5 \mathrm{ppmv}(50 \%)$. This structure is not observed by MIPAS. Also between 12 and $20 \mathrm{~km}$ the POAM III $\mathrm{H}_{2} \mathrm{O}$ abundances are still larger than those of MIPAS.

The $\chi_{\text {red. }}^{2}$ values used for precision validation are far larger than the confidence range for all altitudes except near $29 \mathrm{~km}$ and near $16 \mathrm{~km}$. The large $\chi_{\text {red. }}^{2}$ values near $21 \mathrm{~km}$ occur at the same altitude as the large maximum in the bias profile.

Comparison of MIPAS with the smoothed POAM III profiles (Figs. 14 and 15, red lines) again shows a similar behaviour for the bias determination compared to the original profiles with small structures being smoothed but the overall shape remaining the same. $\chi_{\text {red. }}^{2}$ is dramatically reduced by the smoothing for all altitudes below $30 \mathrm{~km}$, where it falls in the range of confidence or even below. This indicates that the large $\chi_{\text {red. }}^{2}$ of the comparison of the original profiles is explained by the different altitude resolution of the MIPAS and POAM III retrievals. The sounded atmosphere seems to have been characterized by $\mathrm{H}_{2} \mathrm{O}$ vertical profiles with pronounced small-scale structures even above the hygropause. Otherwise the effect of smoothing would not have been that dramatic. 

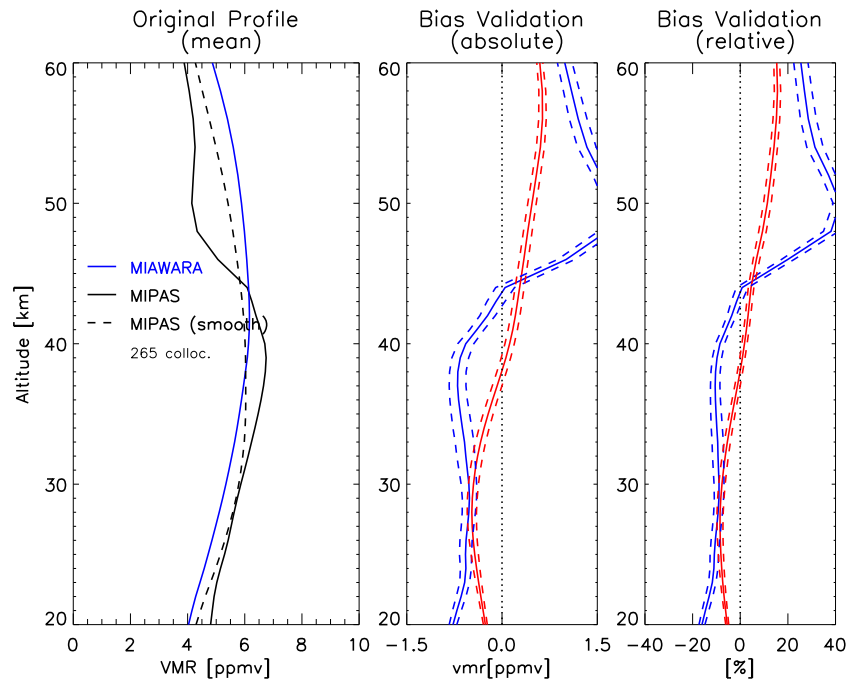

Fig. 16. Bias between MIPAS and ground based MIAWARA water vapour measurements recorded in Sodankylä. Blue: MIAWARA original profiles. Dashed: MIPAS profiles smoothed with MIAWARA averaging kernels. Difference plots: Blue: MIPAS original profiles. Red: MIPAS profiles smoothed with MIAWARA averaging kernels. For details, see Fig. 2.

\subsection{Comparison with ground based remote sensing instruments}

\subsubsection{MIAWARA}

The Middle Atmospheric Water Vapour Radiometer (MIAWARA) is a microwave radiometer using a water vapour line at $22.235 \mathrm{GHz}$. It is operated by the Institute of Applied Physics of the University of Bern, Switzerland and measures water vapour profiles in an altitude range from about 20 to $80 \mathrm{~km}$ with a vertical resolution of about 8 $10 \mathrm{~km}$. Further details on the instrument can be found in Deuber et al. (2004). Until autumn 2003 MIAWARA was operated in Bern, Switzerland $\left(46.95^{\circ} \mathrm{N} 7.450^{\circ} \mathrm{E}\right)$ and in winter 2004 it was operated in Sodankylä, Finland $\left(67.37^{\circ} \mathrm{N} 26.63^{\circ} \mathrm{E}\right)$ during the LAUTLOS-WAVVAP campaign (Lapland Atmosphere-Biosphere Facility (LAPBIAT) upper tropospheric lower stratospheric water vapour validation project) (Deuber et al., 2005). The data presented here are an improved version of water vapour profiles (A. Haefele, personal communication, 2007). The measurement error for MIAWARA is in the range of 15 to $20 \%$ (Deuber et al., 2005). For H2O_V3O_13 only coincidences for the measurements during the LAUTLOS-WAVVAP campaign are available and discussed here.

The vertical resolution of the $\mathrm{H}_{2} \mathrm{O}$ profiles retrieved from the ground based MIAWARA measurements is significantly coarser than that of MIPAS. To assess the influence of smoothing, comparisons were done both with and without

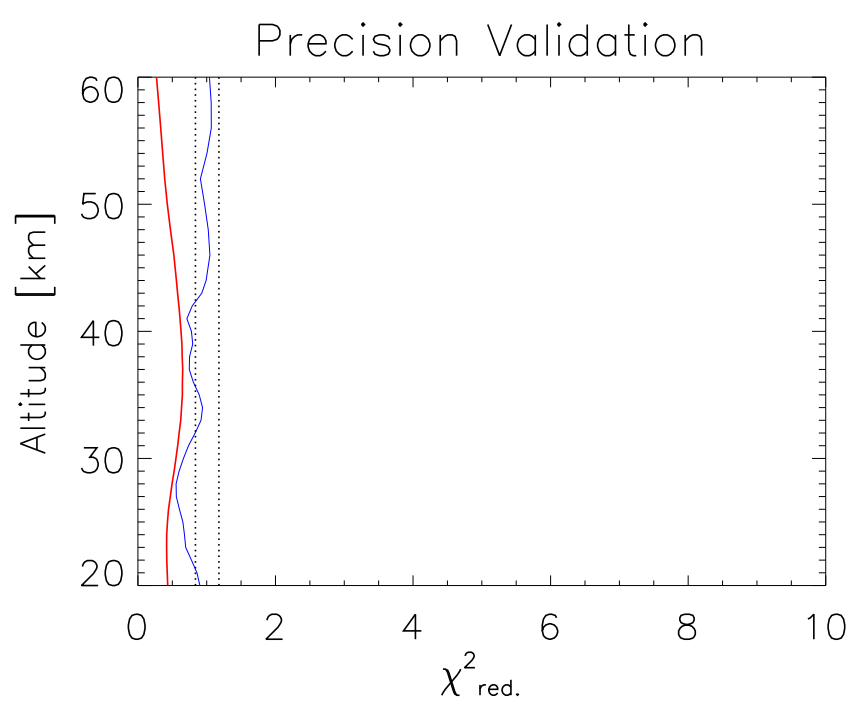

Fig. 17. $\chi^{2}$ analysis for precision validation for MIPAS and ground based MIAWARA water vapour measurements recorded in Sodankylä. Blue: MIPAS original profiles. Red: MIPAS profiles smoothed with MIAWARA averaging kernels. For details, see Fig. 3.

prior smoothing of the better resolved MIPAS profiles by the MIAWARA averaging kernels.

Figure 16 shows the bias between the MIPAS original profiles (solid lines) and MIAWARA original profiles (blue) measured in Sodankylä. For the measurements in Sodankylä 256 suitable collocated measurements were found. The measurements show a wet bias for MIPAS of 10 to $20 \%$ or 0.5 to 1 ppmv compared to the MIAWARA measurements for altitudes below $42 \mathrm{~km}$. Above $43 \mathrm{~km}$ the sign flips and MIPAS profiles are drier by up to $35 \%$ or 1.6 ppmv. As expected, the MIPAS profile is more structured. The corresponding precision validation (Fig. 17, blue lines) shows values inside the confidence limits for altitudes between 42 and $60 \mathrm{~km}$. Below $42 \mathrm{~km}$ the $\chi_{\text {red. }}^{2}$-values are in general smaller than the lower confidence limit. Under consideration of the above determined bias the measurements above $42 \mathrm{~km}$ agree well within the estimated combined random errors.

In order to investigate which part of the differences is to be attributed to the contrast in altitude resolution, the MIPAS profiles were smoothed using the MIAWARA averaging kernels and a priori profiles, which reduced the mean differences between the profiles (Fig. 16, dashed and red line). In particular, the prominent dip in the mean MIPAS profile around $50 \mathrm{~km}$ is smoothed out and no longer visible. The $\chi_{\text {red. values }}^{2}$ calculated on the basis of smoothed MIPAS profiles (Fig. 17, red line) are smaller than the lower confidence limit for all altitudes, which suggests overestimated combined random errors. The comparison shows clearly how strong the vertical smearing of the MIAWARA retrieval influences the result. 

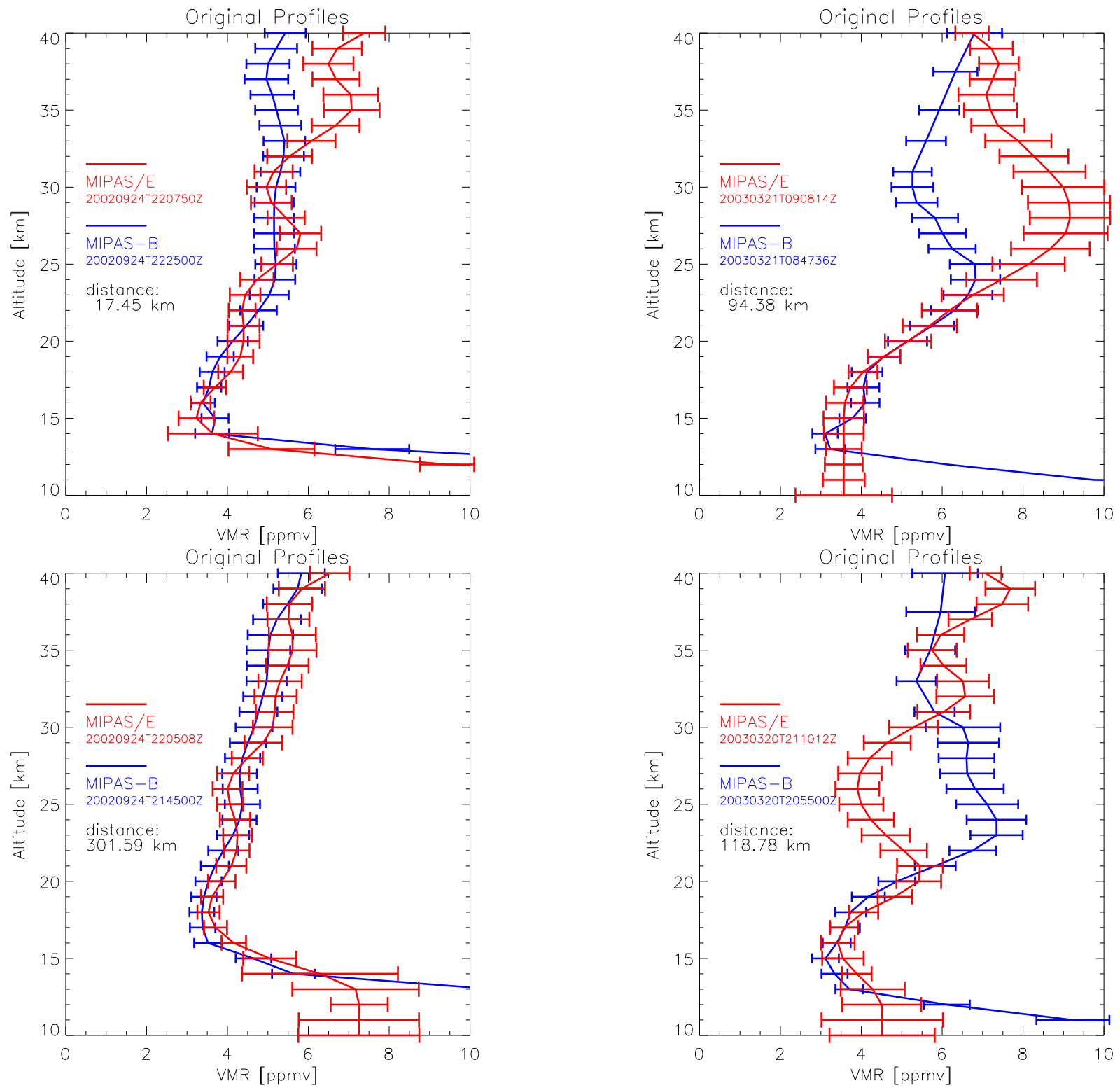

Fig. 18. Individual profiles of two collocated pairs of limb scans measured on 24 September 2002. MIPAS-B: blue, MIPAS/Envisat: red. The error bars show the estimated total error for both instruments.

\subsection{Comparison with airborne and balloon borne re- mote sensing instruments}

\subsubsection{MIPAS-B}

As a precursor of the satellite-borne instrument, MIPAS-B is similar to MIPAS/Envisat in several aspects (Friedl-Vallon et al., 2004). It covers the same spectral range with comparable spectral resolution. Its limb sounding geometry provides similar vertical scan steps during measurements and the ver-

Fig. 19. As Fig. 18 but for arctic measurements in March 2003.

tical FOV is ca. $3 \mathrm{~km}$. The vertical resolution is assumed to be in the same range with approximately $4 \mathrm{~km}$ for MIPAS and $3 \mathrm{~km}$ for MIPAS-B, which allows direct comparison of retrieved profiles.

On 24 September 2002 MIPAS-B was flown during a validation campaign in Aire sur l'Adour, France. During this flight, two limb scans were recorded. One scan, looking to north, provided a nearly exact match with a MIPAS/Envisat scan, both in space and time $(\Delta t$ : about $17 \mathrm{~min}, \delta d: 12$ to $19 \mathrm{~km}$, depending on tangent altitude). A further scan, looking southward, provided another scan which, while still fulfilling the coincidence criteria, is less perfectly coincident. The profiles of the closest scans to each of the MIPAS-B 

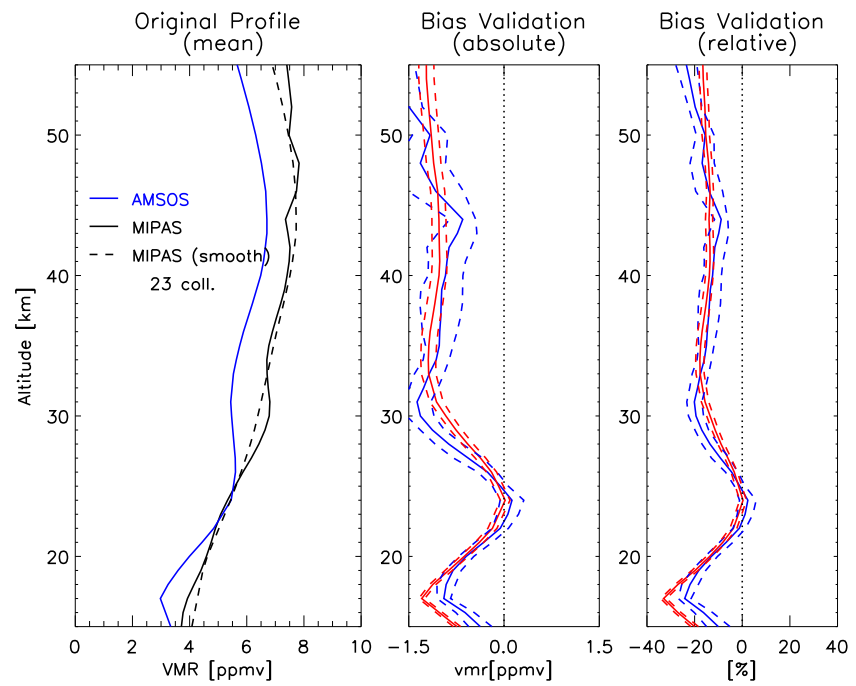

Fig. 20. Bias between MIPAS and AMSOS water vapour measurements. For details, see Fig. 16.

profiles are shown in Fig. 18. For the southward viewing scan, additionally the values of the potential vorticity (PV) at certain reference altitudes were considered as two scans by MIPAS/Envisat are in about the same distance to the MIPASB scan. The MIPAS/Envisat measurement with the smaller difference in the PV values was used for the comparison. The $\mathrm{PV}$ values were obtained from ECMWF reanalysis data. Due to the small sample size, no statistical analysis was made.

On 20 and 21 March 2003, two further MIPAS-B limb measurements were made over Kiruna, Sweden. During this flight, 12 suitable coincidences were obtained. In Fig. 19 the two coincidences with the best coincidence in space, time, and potential vorticity at the tangent point are shown.

For the mid-latitudinal MIPAS-B measurements the agreement is very good and the $\mathrm{H}_{2} \mathrm{O}$ differences are well within the error bars of both instruments. For MIPAS-B the total random error is assumed to be between 5 and $7 \%$. The deviation above $30 \mathrm{~km}$ for the northward looking scan of MIPAS-B can be explained by increasing distance between the tangent points of MIPAS-B and MIPAS/Envisat combined with a strong North-South-gradient observed in water vapour and other trace species. For the comparison of the southward looking scan of MIPAS-B similar air masses were observed according to the $\mathrm{PV}$ ( $\mathrm{PV}$ at $625 \mathrm{~K}$ potential temperature level (approximately $25 \mathrm{~km}$ ): 46.8 PVU (MIPAS-B)45.8 PVU (MIPAS/Envisat)). As both instruments use the same spectral range and measurement principle and considering the fact that coincidences are very close to each other, this result was to be expected.

For the Arctic MIPAS-B measurements the two closest coincidences agree very well for altitudes below $23 \mathrm{~km}$, and reasonably well (still overlapping error bars) up to $25 \mathrm{~km}$. Here the PV values indicate air masses of the same origin (PV at $400 \mathrm{~K}$ potential temperature level (approximately $17 \mathrm{~km}$ ): 11.0 PVU (MIPAS-B) and 10.8 PVU (MIPAS/Envisat) (Fig. 19, upper plot); 9.9 PVU (MIPAS-B) and 9.6 PVU (MIPAS/Envisat) (Fig. 19, lower plot)). For altitudes above 20 to $25 \mathrm{~km}$ the two profiles differ. Here the PV values on according levels of potential temperature indicate that the observed air masses are of different origin. ( $\mathrm{PV}$ at $850 \mathrm{~K}$ potential temperature level (approximately $30 \mathrm{~km}$ ): 522 PVU (MIPAS-B) and 593 PVU (MIPAS/Envisat) (Fig. 19, upper plot); $562 \mathrm{PVU}$ (MIPAS-B) and $766 \mathrm{PVU}$ (MIPAS/Envisat) (Fig. 19, lower plot)). One case, not shown here, shows good agreement for higher altitudes where the PV values of both measurements agree better, while the lower altitudes show larger differences, going along with poorer agreement in PV values.

\subsubsection{AMSOS}

The Airborne Microwave Stratospheric Observing System (AMSOS) is an upward looking passive microwave radiometer which is flown on board a Learjet-35A of the Swiss Air Force during dedicated campaigns (Vasic et al., 2005). It uses a prominent water vapour signature around $183 \mathrm{GHz}$ to determine vertical profiles of water vapour for an altitude range from the plane's flight altitude up to about $60 \mathrm{~km}$.

In September 2002 a campaign of AMSOS was carried out during the measurement period of MIPAS. The campaign lasted about 1 week and latitude ranges from the Arctic to the tropics were covered (Müller et al., 2008; Feist et al., 2007). These authors also compared their measurements to IMKIAA water vapour profiles version H2O_V3O_11 (Müller et al., 2008). All 23 coincidences are north of $75^{\circ}$ N. No distinction between polar vortex measurements and non-vortex air measurements was made then.

The vertical resolution for the AMSOS is estimated to lie in the range of $8 \mathrm{~km}$ (lower stratosphere) to $16 \mathrm{~km}$ (upper stratosphere) and is therefore significantly coarser than MIPAS. As described above for MIAWARA, the influence of smoothing is assessed by considering comparisons both of the original profiles and of the original AMSOS profiles with MIPAS profiles smoothed with AMSOS averaging kernels.

For the comparison of the original profiles, MIPAS has a wet bias of 1 to $1.3 \mathrm{ppmv}$ (15 to 20\%) relative to AMSOS between 15 and $50 \mathrm{~km}$, except for the altitude range between 22 and $25 \mathrm{~km}$, where good agreement is found (Fig. 20). $\chi_{\text {red. }}^{2}$ values are situated around the lower confidence limit for all altitudes for all altitudes between 15 an $50 \mathrm{~km}$ (Fig. 21, blue lines), indicating realistic to conservative error estimates. For AMSOS only the observation error (measurement noise) was used which is in the range of 5 to $8 \%$ (Müller et al., 2008).

In Fig. 20 the bias determination for smoothed MIPAS profiles is shown (dashed and red lines, respectively). The shape of the determined bias is similar to the untreated case. But as expected, some fine structures in the MIPAS profile have disappeared. Only the parts of both profiles where 
the information in the profile is determined by the measurement and not by the a priori were used. Therefore the profiles below $15 \mathrm{~km}$ and above $55 \mathrm{~km}$ are not discussed. The $\chi_{\text {red. }}^{2}$ values are smaller than the lower confidence limit. This may indicate that the combined random error budget for the smoothed MIPAS and the untreated AMSOS profiles is overestimating the total random error.

The comparison by Müller et al. (2008) shows similar results with a dry bias of AMSOS compared to MIPAS. For the altitude range between 20 and $30 \mathrm{~km}$ the bias between AMSOS and H2O_V3O_13 is smaller than in the previous study. For altitudes above approximately $30 \mathrm{~km}$ the biases are similar.

\subsubsection{DLR-DIAL}

Comparisons of MIPAS V3O_H2O_13 data with the zenithviewing LIDAR instrument DIAL flown on the Falcon research aircraft have been published before (Kiemle et al., 2008) and we repeat here the main findings. The zenithviewing water vapor differential absorption lidar (DIAL) was flown on board of the Falcon research aircraft of the Deutsches Zentrum für Luft und Raumfahrt (DLR) during the Tropical Convection, Cirrus and Nitrogen Oxides Experiment (TROCCINOX) in February/March 2004 and 2005 in Brazil. The DIAL measurements were performed alternatively on three water vapor absorption lines of different strength around $940 \mathrm{~nm}$. Sensitivity analyses reveal an accuracy of $5 \%$ between altitudes of 8 and $16 \mathrm{~km}$.

Five tropical DIAL under-flights of MIPAS for February/March 2004 were found. In order to improve the number of co-incidences, Kiemle et al. (2008) performed forward or backward trajectories using the NOAA HYSPLIT online transport model (Draxler and Rolph, 2003) which helped to select the closest MIPAS profiles and estimate the average distance to the DIAL measurements. Cases with distances larger than meso-scales $(500 \mathrm{~km})$ were rejected. Despite careful selection, situations with different meteorological conditions could not always been avoided, in particular because temporal coincidence criteria had to be rather weak $(5-8 \mathrm{~h})$. The MIPAS-DIAL comparisons revealed a mean difference of approximately $8.3 \% \pm 48.5 \%(-3.2 \% \pm 48.8 \%$ above $12 \mathrm{~km}$ altitude) at an average distance of $315 \mathrm{~km}$. The large scatter was attributed to instrument precision (assessed above), atmospheric temporal and spatial heterogeneity, and to the relatively large average distances between the probed air masses, mainly due to the large time difference between the measurements $(6 \mathrm{~h}$ on average, making a considerable difference regarding the diurnal variation of high-reaching convection). The standard deviation of the mean (which is equal to the standard deviation divided by the square root of the number of profiles) was found to be altitude dependent between 10 and $20 \%$. A significant bias was consequently found by Kiemle et al. (2008) only for altitudes below $12 \mathrm{~km}$.

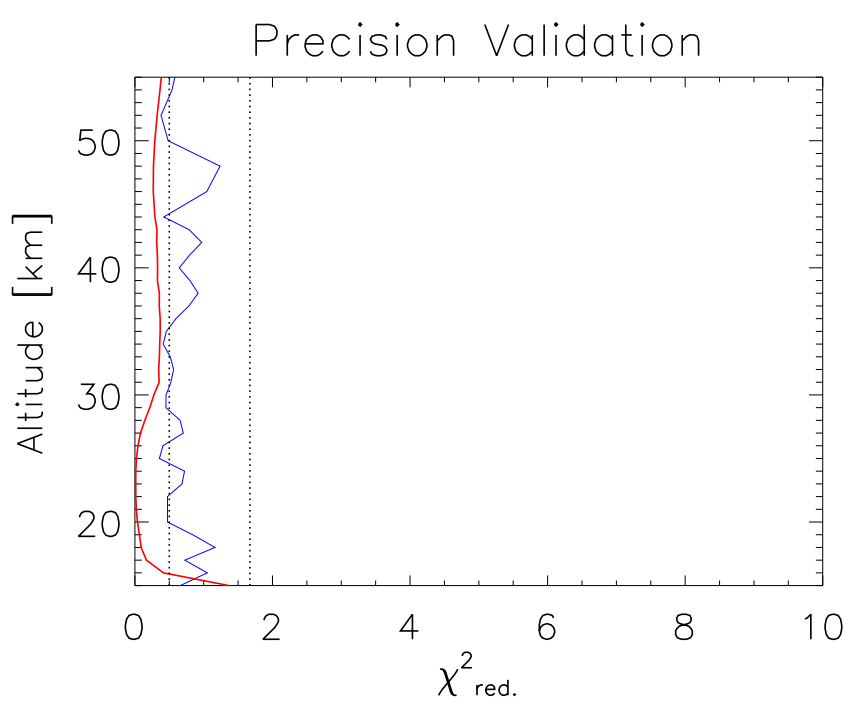

Fig. 21. $\chi^{2}$ analysis for precision validation for MIPAS and AMSOS water vapour measurements. For details, see Fig. 17.

\subsection{Comparison with in situ sensors}

\subsubsection{FLASH-B}

During the LAUTLOS-WAVVAP campaign several in situ sensors for measuring water vapour and/or relative humidity were launched with balloons with the aim of characterizing and validating measurements of currently used radiosonde types. One of the reference instruments used was the FLuorescent Advanced Stratospheric Hygrometer for Balloon (FLASH-B). It uses the photodissociation of water vapour molecules when exposed to radiation at the wavelength $\lambda=121.6 \mathrm{~nm}($ Lyman- $\alpha)$. The instrument is described by Yushkov et al. $(1998,2000)$.

During the ascent of the balloon-borne in situ instrument, humid tropospheric air is lifted up by the platform, which leads to a high bias in the recorded $\mathrm{H}_{2} \mathrm{O}$ concentrations. To avoid these artefacts, only data from the instruments descent are used for comparison.

Although water vapour profiles measured by FLASH have a very high vertical resolution, the profiles were not degraded by the MIPAS averaging kernels prior to comparison. This is, because the FLASH-B profiles cover quite a small altitude range (ca. $15 \mathrm{~km}$ ), and edge effects of the application of the MIPAS averaging kernel would dominate the intercomparison. Due to the small sample size no meaningful statistical analysis can be made. Obviously MIPAS cannot resolve all fine structures seen by FLASH-B, but in many cases the profiles agree within their error bars (Fig. 22). The error for the FLASH-B measurements was estimated to be $10 \%$. In three cases MIPAS even resolves the hygropause. 

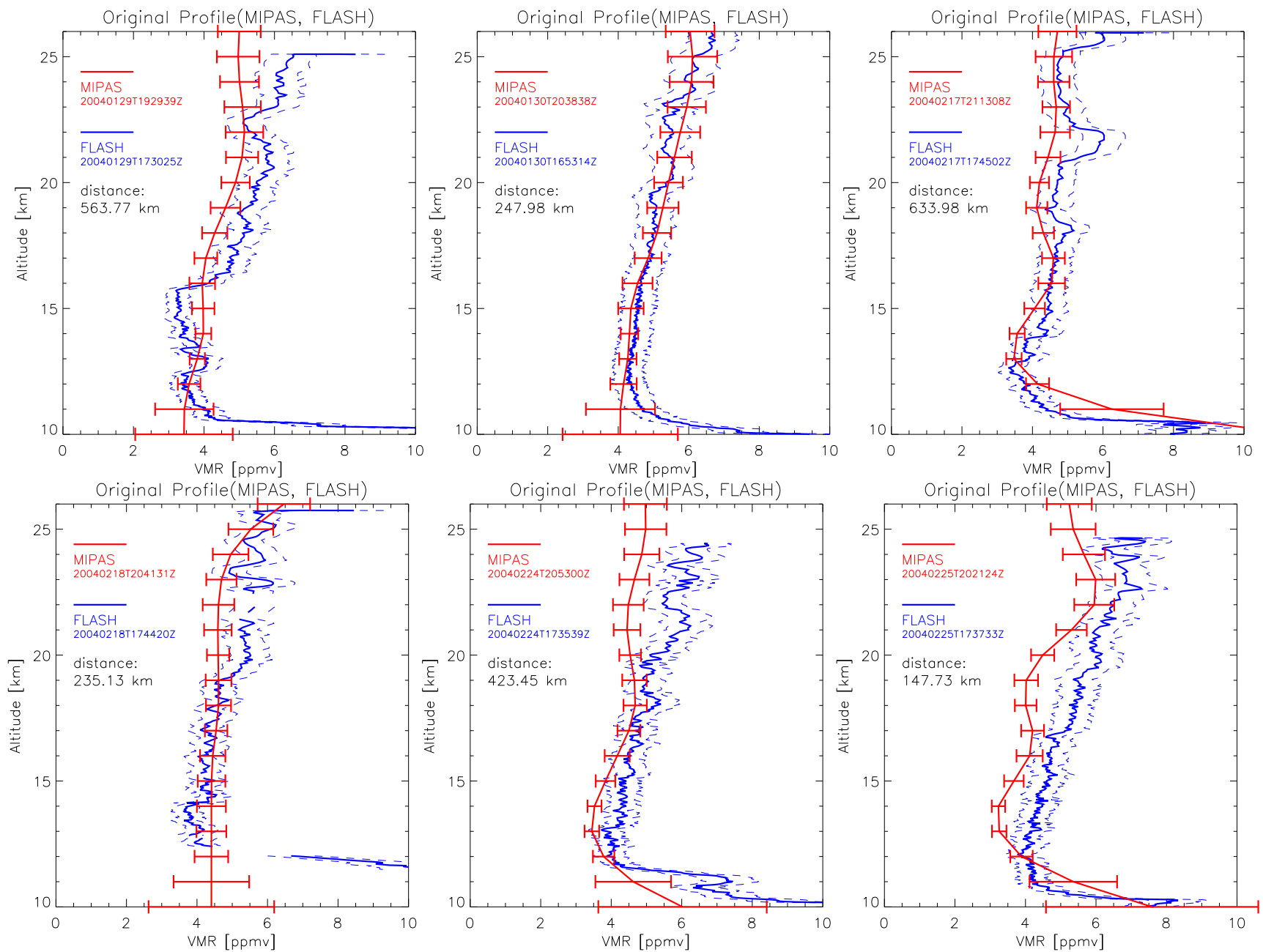

Fig. 22. FLASH-B (blue) and MIPAS (red) $\mathrm{H}_{2} \mathrm{O}$ profiles for six coincidences the dashed lines indicate the error bars of the FLASH-B measurement.

\subsubsection{NOAA frost point hygrometer}

The National Oceanic and Atmospheric Administration (NOAA) operates a cryogenic frostpoint hygrometer which has provided the long time-series of water vapour profiles over Boulder, CO, USA (Oltmans et al., 2000). Due to its known high accuracy the NOAA frostpoint hygrometer (FPH) is often commonly used as a reference for comparison and validation of in situ water vapour measurements in the upper troposphere and lower stratosphere. Together with the FLASH-B instrument, it was operated during LAUTLOSWAVVAC in 2004 as reference to assess the accuracy of different radiosonde humidity sensors. As for the FLASH-B instrument, only data from the instruments descent are used to avoid artefacts. Also here the original water vapour profiles measured by NOAA FPH were used for the comparison due to the edge effect with the application of the MIPAS averaging kernel. The NOAA-FPH data shown here are corrected and the sampling is reduced to represent a vertical resolution of $1 / 4 \mathrm{~km}$ (H. Vömel, personal communication, 2008). For NOAA FPH the total error was estimated to be $10 \%$. Due to the small sample size we were forced to perform individual profile comparison instead of statistical analysis. The agreement in the four comparisons is quite different (Fig. 23). Of course MIPAS cannot reproduce all the fine structures seen by the NOAA FPH but the $\mathrm{H}_{2} \mathrm{O}$ amounts in the lowermost stratosphere agree well within the error bars in three of four cases. In one case MIPAS even resolves the hygropause quite well. Above about $20 \mathrm{~km}$ MIPAS seems to have a slight dry bias compared to FLASH-B and NOAA FPH.

\subsubsection{M55-FISH}

The Fast In-Situ Hygrometer (FISH) was operated on board the Russian high altitude research aircraft Geophysica M55. FISH measures the total water amount in situ using 

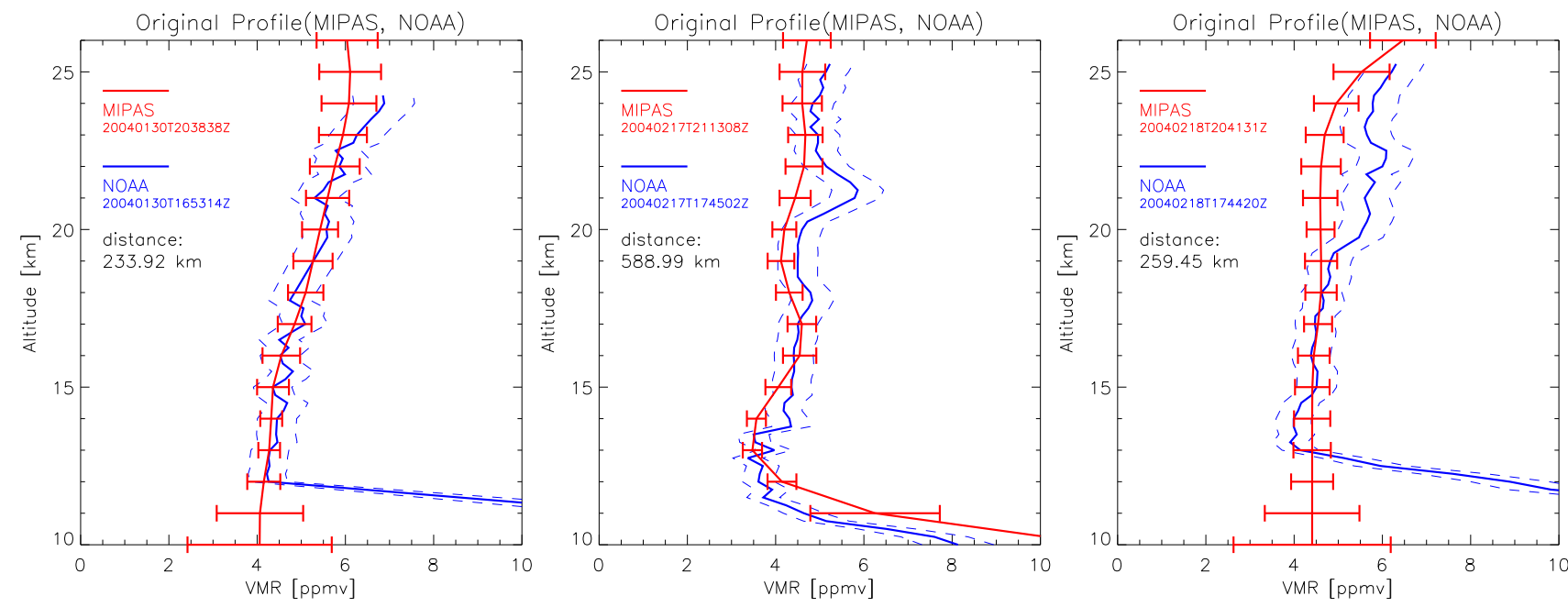

Fig. 23. Profiles of MIPAS (red) and NOAA (blue) for three coincidences, the dashed lines indicate the error bars of the NOAA measurement.

Lyman- $\alpha$-flourescence of water molecules. The Geophysica M55 aircraft is flying at altitudes up to $20 \mathrm{~km}$ and thus observes the stratosphere at mid- and high latitudes. As clouds are confined to the troposphere and no polar stratospheric clouds were encountered during the flights, it is assumed that stratospheric measurements represent pure water vapour measurements. During the Envisat validation campaign in October 2002 and the EUPLEX campaign in Winter 2003 measurements collocated with MIPAS/Envisat measurements were taken. Since humid tropospheric air is lifted up during the ascent by the airplane, leading to a high bias in the recorded values, only data from the descending part of the flights are used. The comparison of the original data is shown, since the boundary effects of the smoothing procedure reduces the usable altitude range to a few kilometers. The accuracy of the in situ measurements by FISH is estimated at about $8 \%$ (Voigt et al., 2007).

In Fig. 24 the individual original high resolution FISH profiles and the best collocated MIPAS profiles are shown. The profiles from FISH reach up to the maximum flight altitude which is up to $20 \mathrm{~km}$. For the relevant altitude range between approximately 10 and $20 \mathrm{~km}$ the profiles are close to each other. The FISH $\mathrm{H}_{2} \mathrm{O}$ mixing ratios tend to be slightly smaller than those of MIPAS but the differences are within the combined error bars. In some cases the hygropause is well caught by MIPAS but its limited altitude resolution certainly explains discrepancies found in other cases.

For the same reason as for FLASH-B and the NOAA FPH the high resolution of FISH was not degraded to the resolution of MIPAS to avoid edge effects for the restricted altitude range.

\subsection{Comparison to ESA MIPAS water vapour products}

The ESA MIPAS water vapour data product (Raspollini et al., 2006) certainly is not an independent data product because it relies on the same set of measured spectra. Nevertheless, a comparison is considered useful because it highlights differences in the retrieval settings. While both data products rely on the same level-1B product, the retrieval processors are completely independent. They share neither the forward model nor the retrieval scheme nor do these retrievals use the same microwindows. Thus, this comparison is ideal to detect biases caused by the retrieval approach itself. In order to have a sufficiently homogeneous data-set, only northern mid-latitudinal profiles $\left(30^{\circ}-60^{\circ} \mathrm{N}\right)$ were considered. 5644 profiles were used. As expected, the differences are much smaller over the entire altitude range as compared to most of the comparisons with independent measurements (Fig. 25). This is in agreement with the assumption that less than perfect coincidences along with atmospheric variability explain a large portion of the observed systematic differences found in the other comparisons. At the lower end of the profile, the logarithmic IMK-retrieval seems to better resolve the hygropause compared to the linear ESA retrieval. At $1 \mathrm{hPa}$, the ESA profiles are slightly larger than the IMK profiles. This may be attributed to the fact that the ESA retrieval assumes a known profile shape above the uppermost tangent altitude and adjusts the water vapour amount by scaling the upper branch of the profile. Any errors in the assumed profile shape trigger profile oscillations below. If this a priori assumption is systematically wrong, this can explain oscillations with a component which is in phase throughout the comparison sample and thus persists through the averaging process. The positive and negative discrepancies of only $0.3 \mathrm{ppmv}$ at about $40 \mathrm{hPa}$ and $4 \mathrm{hPa}$, respectively are most 

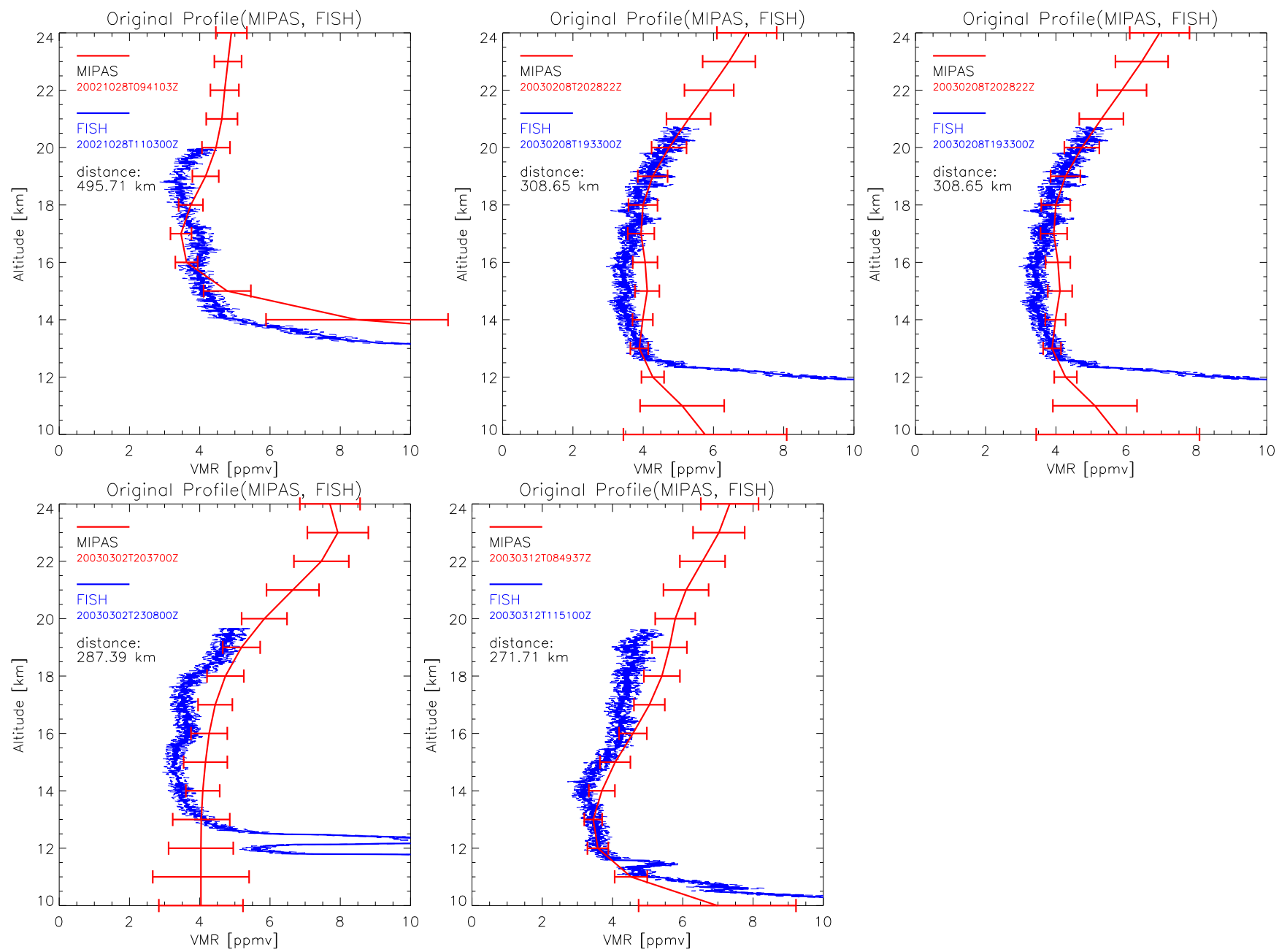

Fig. 24. Collocated original profiles of FISH (blue) and MIPAS (red).

probably due to error propagation triggered by the differences at the higher and lower end of the profile discussed above. While the small differences between the IMK retrievals and the ESA retrievals are statistically significant and exhibit the fact that the retrieval concepts are quite different, the overall agreement provides confidence that the retrievals are basically sound in the sense that there is no major systematic peculiarity in either of them. The pattern of the MIPASIMK vs. MIPAS-ESA bias is not in phase with that of any of the differences between MIPAS-IMK and independent measurements, i.e. there is no evidence that it is due to a particular MIPAS-IMK retrieval artefact.

\section{Conclusions}

\subsection{Bias determination}

There is no clear indication of a bias of MIPAS $\mathrm{H}_{2} \mathrm{O}$ profiles in the stratosphere. Some instruments measure more, others measure less $\mathrm{H}_{2} \mathrm{O}$ than MIPAS. The most striking fact in the synergistic view on the various biases determined from different instruments is that the bias seems to be a function of the wavelength at which the comparison instrument is operated. POAM III, which operates in the visible and UV, measures more water vapour than MIPAS; the agreement with other infrared sensors is quite good in most cases (e.g. ACEFTS, ILAS-II), and the microwave instruments (MIAWARA, AMSOS) see less water vapour than MIPAS. This hints at a possible inconsistency of the spectroscopic data used for analysis of the measurements. On the other hand, Lumpe et al. (2006) point out that an inadequate channel characterization may cause the wet bias for POAM-III. This findings suggests that the biases found between MIPAS and the comparison instruments is not a MIPAS-specific problem but a problem of a more general nature. 

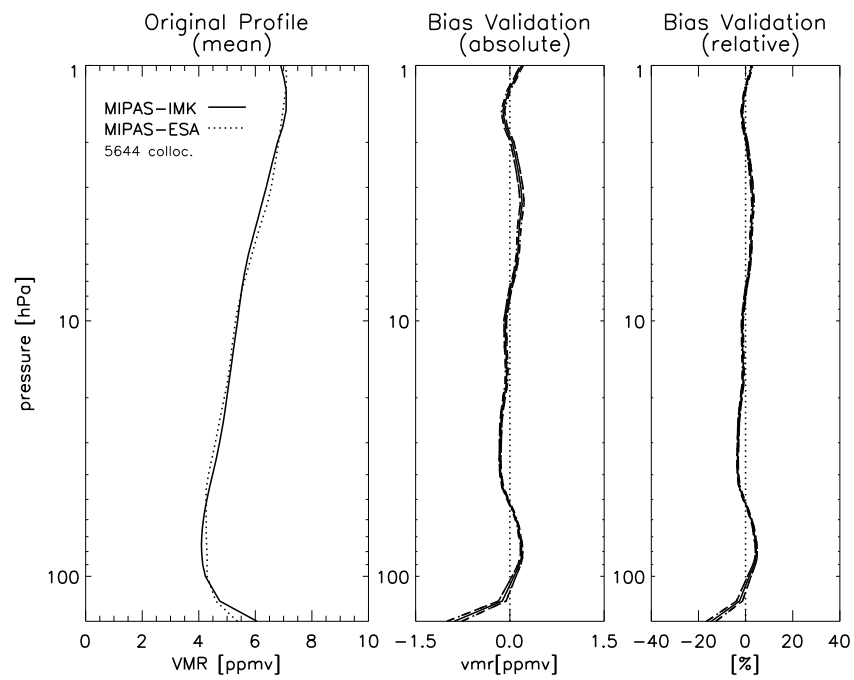

Fig. 25. Comparison of MIPAS $\mathrm{H}_{2} \mathrm{O}$ profiles retrieved by IMK (solid) and the official ESA version 4.61/4.62 $\mathrm{H}_{2} \mathrm{O}$ data product (dotted), northern mid-latitudes, 5644 coincidences.

Table 2. List of the estimated ex ante random errors of all instruments.

\begin{tabular}{lrr}
\hline Instrument & $\begin{array}{r}\text { Altitude range } \\
(\mathrm{km})\end{array}$ & $\begin{array}{r}\text { Random error } \\
(\%)\end{array}$ \\
\hline MIPAS (IMK/IAA) & $15-50$ & $5-10$ \\
HALOE & $12-50$ & $14-27$ \\
ACE-FTS (only meas. noise) & $15-50$ & $1-3$ \\
ILAS-II & $15-50$ & $3-20$ \\
POAM III & $10-50$ & $4-7$ \\
MIAWARA & $20-65$ & $10-20$ \\
MIPAS-B & $10-40$ & $5-7$ \\
AMSOS (only meas. noise) & $15-60$ & $5-8$ \\
FLASH-B & $10-25$ & 10 \\
NOAA & $10-25$ & 10 \\
FISH & $10-22$ & 8 \\
\hline
\end{tabular}

\subsection{Precision validation}

The results of our simplified $\chi^{2}$-analysis seem a bit ambiguous. For instruments with a realistic error estimation (see Table 2 for the assigned random errors), partly including several error sources, such as HALOE, MIAWARA and AMSOS the

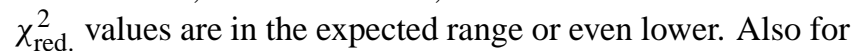
Northern Hemisphere measurements of ILAS-II and POAM III the $\chi_{\text {red. }}^{2}$ values are in the expected range. These results suggest that it is very unlikely that large $\chi_{\text {red. }}^{2}$ values in other comparisons are caused by underestimated MIPAS random errors alone, since this would require largely overestimated random errors of the comparison instruments. In some cases $\chi_{\text {red. }}^{2}$ values are so high that they cannot be explained by the combined random error bars of the comparison. One possible explanations of high $\chi_{\text {red. }}^{2}$ values in some cases is that the uncertainty assigned to the comparison instrument might not cover the full random error but only some of its components. This is clearly visible for the comparison with ACE-FTS for which only the small measurement noise was available as random error. Furthermore the comparisons with Southern Hemisphere measurements of POAM III and ILAS-II suggest that here the assigned uncertainty is to small. However, for ILAS-II the variability in vicinity to the vortex boundary and the different vertical resolution of the compared instruments introduces an additional uncertainty which is not accounted for by the assumed error budgets. The latter comparisons showed also increased biases compared to the Northern Hemisphere measurements. Another explanation is that the natural variability along with less than perfect coincidences contribute to the uncertainty of the difference. Comparisons with particular good coincidences indeed stand out with particularly small $\mathrm{H}_{2} \mathrm{O}$ differences (MIPAS-B, FISH) at altitudes where according to the PV values similar air masses were compared. In view of these arguments, we conclude that there is no evidence of a general underestimation of MIPAS random retrieval errors.

Acknowledgements. The authors like to thank ESA for making level-1 data available. We further thank Karl Hoppel and the POAM III team who have provided POAM III water vapour data. This work has partly been funded by BMBF under contract no. 50 EE 0512. The ACE satellite is funded primarily by the Canadian Space Agency. The ILAS-II project was funded by the Ministry of the Environment Japan, (MOE). A part of this research was supported by the Global Environment Research Fund (GERF) provided by the MOWE (A-10 and A071). The FISH experiment was funded by the BMBF (Envisat Validation Program), the HGF-Vernetzungsfond (50 EE 0018, 50 EE 0203, 01 SF 9955), and the Geophysica was funded by the APE-INFRA-project (EVR1-CT-2001-40020). The work of the IMK MIPAS/Envisat group has been funded by EC via the Integrated Project SCOUT-O3.

Edited by: J.-P. Pommereau

\section{References}

Bernath, P. F., McElroy, C. T., Abrams, M. C., Boone, C. D., Butler, M., Camy-Peyret, C., Carleer, M., Clerbaux, C., Coheur, P.F., Colin, R., DeCola, P., De Mazière, M., Drummond, J. R., Dufour, D., Evans, W. F. J., Fast, H., Fussen, D., Gilbert, K., Jennings, D. E., Llewellyn, E. J., Lowe, R. P., Mahieu, E., McConnell, J. C., McHugh, M., McLeod, S. D., Michaud, R., Midwinter, C., Nassar, R., Nichitiu, F., Nowlan, C., Rinsland, C. P., Rochon, Y. J., Rowlands, N., Semeniuk, K., Simon, P., Skelton, R., Sloan, J. J., Soucy, M.-A., Strong, K., Tremblay, P., Turnbull, D., Walker, K. A., Walkty, I., Wardle, D. A., Wehrle, V., Zander, R., and Zou, J.: Atmospheric Chemistry Experiment (ACE): Mission overview, Geophys. Res. Lett., 32, L15S01, doi:10.1029/2005GL022386, 2005. 
Boone, C. D., Nassar, R., Walker, K. A., Rochon, Y., McLeod, S. D., Rinsland, C. P., and Bernath, P. F.: Retrievals for the atmospheric chemistry experiment Fourier- transform spectrometer, Appl. Optics, 44(33), 7218-7231, 2005.

Carleer, M. R., Boone, C. D., Walker, K. A., Bernath, P. F., Strong, K., Sica, R. J., Randall, C. E., Vömel, H., Kar, J., Höpfner, M., Milz, M., von Clarmann, T., Kivi, R., Valverde-Canossa, J., Sioris, C. E., Izawa, M. R. M., Dupuy, E., McElroy, C. T., Drummond, J. R., Nowlan, C. R., Zou, J., Nichitiu, F., Lossow, S., Urban, J., Murtagh, D., and Dufour, D. G.: Validation of water vapour profiles from the Atmospheric Chemistry Experiment (ACE), Atmos. Chem. Phys. Discuss., 8, 4499-4559, 2008, http://www.atmos-chem-phys-discuss.net/8/4499/2008/.

Deuber, B., Haefele, A., Feist, D. G., Martin, L., Kämpfer, N., Nedoluha, G. E., Yushkov, V., Khaykin, S., Kivi, R., and Vömel, H.: Middle Atmospheric Water Vapour Radiometer (MIAWARA): Validation and first results of the LAPBIAT Upper Tropospheric Lower Stratospheric Water Vapour Validation Project (LAUTLOS-WAVVAP) campaign, J. Geophys. Res., 110, D13306, doi:10.1029/2004JD005543, 2005.

Deuber, B., Kämpfer, N., and Feist, D. G.: A new 22-GHz radiometer for middle atmospheric water vapour profile measurements, IEEE Trans. Geosci. Rem. Sens., 42(5), 974-984, 2004.

Draxler, R. R. and Rolph, G. D.: Hysplit (hybrid single-particle lagrangian integrated trajectory) model, access via NOAA ARL READY Website (http://www.arl.noaa.gov/ready/hysplit4.html), 2003

Feist, D. G., Geer, A. J., Müller, S., and Kämpfer, N.: Middle atmosphere water vapour and dynamical features in aircraft measurements and ECMWF analyses, Atmos. Chem. Phys., 7, 52915307, 2007, http://www.atmos-chem-phys.net/7/5291/2007/.

Fischer, H., Birk, M., Blom, C., Carli, B., Carlotti, M., von Clarmann, T., Delbouille, L., Dudhia, A., Ehhalt, D., Endemann, M., Flaud, J. M., Gessner, R., Kleinert, A., Koopman, R., Langen, J., López-Puertas, M., Mosner, P., Nett, H., Oelhaf, H., Perron, G., Remedios, J., Ridolfi, M., Stiller, G., and Zander, R.: MIPAS: an instrument for atmospheric and climate research, Atmos. Chem. Phys., 8, 2151-2188, 2008,

http://www.atmos-chem-phys.net/8/2151/2008/.

Friedl-Vallon, F., Maucher, G., Kleinert, A., Lengel, A., Keim, C., Oelhaf, H., Fischer, H., Seefeldner, M., and Trieschmann, O.: Design and characterisation of the ballon-borne Michelson Interferometer for Passive Atmospheric Sounding (MIPAS-B2), Appl. Optics, 43(16), 3335-3355, 2004.

Griesfeller, A., von Clarmann, T., Griesfeller, J., Höpfner, M., Milz, M., Nakajima, H., Steck, T., Sugita, T., Tanaka, T., and Yokota, T.: Intercomparison of ILAS-II version 1.4 and version 2 target parameters with MIPAS-Envisat measurements, Atmos. Chem. Phys., 8, 825-843, 2008,

http://www.atmos-chem-phys.net/8/825/2008/.

Harries, J. E., Russell III, J. M., Tuck, A. F., Gordley, L. L., Purcell, P., Stone, K., Bevilacqua, R. M., Gunson, M., Nedoluha, G., and Traub, W. A.: Validation of measurements of water vapor from the halogen occultation experiment (HALOE), J. Geophys. Res., 101(D6), 10205-10216, 1996.

Kiemle, C., Wirth, M., Fix, A., Ehret, G., Schumann, U., Gardiner, T., Schiller, C., Sitnikov, N., and Stiller, G.: First airborne water vapor lidar measurements in the tropical upper troposphere and mid-latitudes lower stratosphere: accuracy evaluation and intercomparisons with other instruments, Atmos. Chem. Phys., 8, 5245-5261, 2008,

http://www.atmos-chem-phys.net/8/5245/2008/.

Kley, D., Stone, E. J., Henderson, W. R., Drummond, J. W., Harrop, W. J., Schmeltekopf, A. L., Thompson, T. L., and Winkler, R. H.: In situ measurements of the mixing ratio of water vapor in the stratosphere, J. Atmos. Sci., 36, 2513-2524, 1979.

Lucke, R. L., Korwan, D. R., Bevilacqua, R. M., Hornstein, J. S., Shettle, E. P., Chen, D. T., Daehler, M., Lumpe, J. D., Fromm, M. D., Debrestian, D., Neff, B., Squire, M., König-Langlo, G., and Davies, J.: The polar ozone and aerosol measurement (POAM) III instrument and early validation results, J. Geophys. Res., 104(D15), 18785-18799, 1999.

Lumpe, J., Bevilacqua, R., Randall, C., Nedoluha, G., Hoppel, K., Russell, J., Harvey, V. L., Schiller, C., Sen, B., Taha, G., Toon, G., and Vömel, H.: Validation of Polar Ozone and Aerosol Measurement (POAM) III version 4 stratospheric water vapor, J. Geophys. Res., 111, D11301, doi:10.1029/2005JD006763, 2006.

Milz, M., von Clarmann, T., Fischer, H., Glatthor, N., Grabowski, U., Höpfner, M., Kellmann, S., Kiefer, M., Linden, A., Mengistu Tsidu, G., Steck, T., Stiller, G. P., Funke, B., López-Puertas, M., and Koukouli, M. E.: Water vapor distributions measured with the Michelson Interferometer for Passive Atmospheric Sounding on board Envisat (MIPAS/Envisat), J. Geophys. Res., 110, D24307, doi:10.1029/2005JD005973, 2005.

Müller, S. C., Kämpfer, N., Feist, D. G., Haefele, A., Milz, M., Sitnikov, N., Schiller, C., Kiemle, C., and Urban, J.: Validation of stratospheric water vapour measurements from the airborne microwave radiometer AMSOS, Atmos. Chem. Phys., 8, 31693183, 2008, http://www.atmos-chem-phys.net/8/3169/2008/.

Nakajima, H., Sugita, T., Yokota, T., Kobayashi, H., Sasano, Y., Ishigaki, T., Mogi, Y., Araki, N., Waragai, K., Kimura, N., Iwazawa, T., Kuze, A., Tanii, J., Kawasaki, H., Horikawa, M., Togami, T., and Uemura, N.: Characteristics and performance of the Improved Limb Atmospheric Spectrometer-II (ILAS-II) on board the ADEOS-II satellite, J. Geophys. Res., 111, D11S01, doi:10.1029/2005JD006334, 2006.

Nett, H., Carli, B., Carlotti, M., Dudhia, A., Fischer, H., Flaud, J.M., Perron, G., Raspollini, P., and Ridolfi, M.: MIPAS ground processor and data products, in: Proc. IEEE 1999 International Geoscience and Remote Sensing Symposium, 28 June-2 July 1999, Hamburg, Germany, pp 1692-1696, 1999.

Oltmans, S. J., Vömel, H., Hofmann, D. J., Rosenlof, K. H., and Kley, D.: The increase in stratospheric water vapor from ballooneborne, frostpoint hygrometer measurements at Washington, D.C., and Boulder, Colorado, Geophys. Res. Lett., 27(21), 34533456, 2000.

Raspollini, P., Belotti, C., Burgess, A., Carli, B., Carlotti, M., Ceccherini, S., Dinelli, B. M., Dudhia, A., Flaud, J.-M., Funke, B., Höpfner, M., López-Puertas, M., Payne, V., Piccolo, C., Remedios, J. J., Ridolfi, M., and Spang, R.: MIPAS level 2 operational analysis, Atmos. Chem. Phys., 6, 5605-5630, 2006, http://www.atmos-chem-phys.net/6/5605/2006/.

Ridolfi, M., Carli, B., Carlotti, M., von Clarmann, T., Dinelli, B., Dudhia, A., Flaud, J.-M., Höpfner, M., Morris, P. E., Raspollini, P., Stiller, G., and Wells, R. J.: Optimized forward and retrieval scheme for MIPAS near-real-time data processing, Appl. Optics, 39(8), 1323-1340, 2000.

Rodgers, C. D.: Inverse Methods for Atmospheric Sounding: The- 
ory and Practice, volume 2 of "Series on Atmospheric, Oceanic and Planetary Physics", edited by: Taylor, F. W., World Scientific, 2000.

Rodgers, C. D. and Connor, B. J.: Intercomparison of remote sounding instruments, J. Geophys. Res., 108(D3), 4116, doi:10.1029/2002JD002299, 2003.

Russell III, J. M., Gordley, L. L., Park, J. H., Drayson, S. R., Hesketh, W. D., Cicerone, R. J., Tuck, A. F., Frederick, J. E., Harries, J. E., and Crutzen, P. J.: The halogen occultation experiment, J. Geophys. Res., 98, 10777-10797, 1993.

Spang, R., Remedios, J. J., and Barkley, M. P.: Colour indices for the detection and differentiation of cloud types in infra-red limb emission spectra, Adv. Space Res., 3, 1041-1047, 2004.

SPARC: SPARC assessment of upper tropospheric and stratospheric water vapour, WCRP - 113, WMO/TD - No. 1043, SPARC Report No. 2, 2000.

Vasic, V., Feist, D., Müller, S., and Kämpfer, N.: An airborne radiometer for stratospheric water vapor measurements at $183 \mathrm{ghz}$, IEEE Trans. Geosci. Rem. Sens., 43(7), 1563-1570, 2005.

Voigt, C., Kärcher, B., Schlager, H., Schiller, C., Krämer, M., de Reus, M., Vössing, H., Borrmann, S., and Mitev, V.: In-situ observations and modeling of small nitric acid-containing ice crystals, Atmos. Chem. Phys., 7, 3373-3383, 2007, http://www.atmos-chem-phys.net/7/3373/2007/.

von Clarmann, T.: Validation of remotely sensed profiles of atmospheric state variables: strategies and terminology, Atmos. Chem. Phys., 6, 4311-4320, 2006, http://www.atmos-chem-phys.net/6/4311/2006/. von Clarmann, T., Ceccherini, S., Doicu, A., Dudhia, A., Funke, B., Grabowski, U., Hilgers, S., Jay, V., Linden, A., LópezPuertas, M., Martín-Torres, F.-J., Payne, V., Reburn, J., Ridolfi, M., Schreier, F., Schwarz, G., Siddans, R., and Steck, T.: A blind test retrieval experiment for infrared limb emission spectrometry, J. Geophys. Res., 108(D23), 4746, doi:10.1029/2003JD003835, 2003.

von Clarmann, T., De Clercq, C., Ridolfi, M., Höpfner, M., and Lambert, J.-C.: The horizontal resolution of MIPAS, Atmos. Meas. Tech., 2, 47-54, 2009, http://www.atmos-meas-tech.net/2/47/2009/.

Yokota, T., Nakajiama, H., Sugita, T., Tsubaki, H., Itou, Y., Kaji, M., Suzuki, M., Kanzawa, H., Park, J. H., and Sasano, Y.: Improved Limb Atmospheric Spectrometer (ILAS) data retrieval algorithm for Version 5.20 gas profile products, J. Geophys. Res., 107(D24), 8216, doi:10.1029/2001JD000628, 2002.

Yushkov, V., Astakhov, V., and Merkulov, S.: Optical balloon hygrometer for upper-troposphere and stratosphere water vapor measurements, in: Optical Remote Sensing of the Atmosphere and Clouds, edited by: Wang, J., Wu, B., Ogawa, T., and Guans, Z.-H., 3501, 439-445, 1998.

Yushkov, V., Merkulov, S., Astakhov, V., Pommereau, J. P., and Garnier, A.: A Lyman alpha hygrometer for long duration IR Montgolfier during the THESEO Lagrangian Experiment, in: Proc. 5th European Ozone Workshop, 73, 400-403, 2000. 